\title{
Directing the Total Program of Agricultural Education as Perceived by Retired Secondary Agriculture Instructors in West Virginia
}

Dylan Demosthenes Johnson

Follow this and additional works at: https://researchrepository.wvu.edu/etd

\footnotetext{
Recommended Citation

Johnson, Dylan Demosthenes, "Directing the Total Program of Agricultural Education as Perceived by Retired Secondary Agriculture Instructors in West Virginia" (2016). Graduate Theses, Dissertations, and Problem Reports. 5897.

https://researchrepository.wvu.edu/etd/5897

This Thesis is protected by copyright and/or related rights. It has been brought to you by the The Research Repository @ WVU with permission from the rights-holder(s). You are free to use this Thesis in any way that is permitted by the copyright and related rights legislation that applies to your use. For other uses you must obtain permission from the rights-holder(s) directly, unless additional rights are indicated by a Creative Commons license in the record and/ or on the work itself. This Thesis has been accepted for inclusion in WVU Graduate Theses, Dissertations, and Problem Reports collection by an authorized administrator of The Research Repository @ WVU. For more information, please contact researchrepository@mail.wvu.edu.
} 
Directing the Total Program of Agricultural Education as Perceived by Retired Secondary Agriculture Instructors in West Virginia

\title{
Dylan Demosthenes Johnson
}

Thesis submitted to the Davis College of Agriculture, Natural Resources and Design at West Virginia University in partial fulfillment of the requirements for the degree of

\author{
Master of Science \\ in \\ Agricultural and Extension Education \\ Stacy A. Gartin, Ph.D., Chair \\ Harry N. Boone, Jr., Ph.D. \\ Jessica M. Blythe, Ph.D.
}

School of Design and Community Development

Morgantown, West Virginia

2016

Keywords: Agriculture Education, Agriculture, Education

Copyright 2016 Dylan D. Johnson 


\author{
ABSTRACT \\ Directing the Total Program of Agricultural Education as Perceived \\ by Retired Secondary Agriculture Instructors \\ in West Virginia \\ Dylan D. Johnson
}

The purpose of this study was to determine retired secondary agriculture educators' perceptions on the various challenges, barriers, as well as successes and satisfaction of teaching high school agriculture in West Virginia. The researcher chose to conduct a qualitative study through semi-structured interviews. This study was limited to five retired agriculture instructors who retired within the past 10 years. The researcher found the following: high satisfaction in career choice, strong support for the total programs from multiple facets including community, administration and parents, adult education programming is a vital part of the total program and support, FFA is vital to overall student success and development, background greatly influences career choice in agricultural education, balancing life and time is great challenge faced by agriculture instructors, retirement is a strong, fulfilling aspect of career satisfaction. 


\section{DEDICATION}

This thesis is dedicated to the memory of my mother Kristy A. Johnson, who I miss every day. Her passion and commitment to education has served as the inspiration in my career and this study. 


\section{ACKNOWLEDGEMENTS}

To my committee; you are truly an incredible group of friends and scholars. Over the course of this study, I have gained a wealth of knowledge from each of you. Your support has been welcoming, fulfilling and above all, professional. I couldn't have attained this goal without you and I am thankful and blessed to have shared this opportunity to advance agricultural education with individuals who are so committed to the profession.

To Dr. Stacy Gartin, you have been a long-time mentor, advisor, and above all, friend. In every venture you have always supported me and pushed me to do better. For that, I am forever grateful. Your passion and enthusiasm for agriculture and education has served as inspiration to not only me, but to scores before who have walked the sacred halls of academia. None of this would be possible without you.

To Dr. Harry Boone, I have truly enjoyed getting to know you as a teacher and confidant. Your commitment and dedication to not only my educational ventures but the profession as a whole is inspiring. I am forever grateful to have worked under you and be a product of your devotion and professionalism.

To Dr. Jessica Blythe, you will forever be my qualitative research guru. Your inspiration lead me to be the first to "jump off the qualitative research cliff" in the department and I am so honored and blessed to have done so. Your constant advice, insider tips, and countless edits have made this research worthwhile and educational. I thank you for all that you have done and all that you will do for this institution and the profession in the future.

To my crazy officemates Lauren Devine, Mikey Withrow and Samantha Cogle as well as all my graduate school friends; thank you for your countless hours of fun, sing-alongs and random dance parties in the grad office. You made this experience worthwhile and I am glad that I was able to have you along for the ride. Having you around to laugh, cry, and vent frustration to has made grad school bearable and fun. I hope and pray that wherever life takes you, our memories will be cherished forever.

To the five participants in my study, thank you for allowing me to share your story. Your commitment and service to agricultural education in West Virginia will inspire many for years to come. Also, I would like to thank my agriculture teacher, Ken Skidmore, for his support and advice which lead me to enter this profession. I wouldn't be here today if it weren't for you.

Finally, I would like to thank my dad, sister, and all my other family for their constant support and love. I couldn't have done it without you. You have always been there to remind me that I can accomplish anything that I set my mind to. You have truly shaped me into the person that I am today and the person I will be tomorrow. 


\section{TABLE OF CONTENTS}

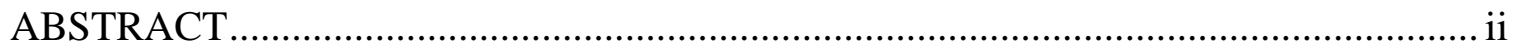

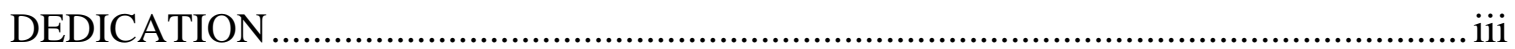

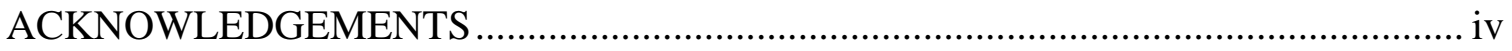

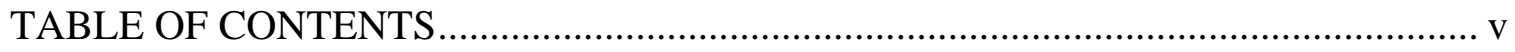

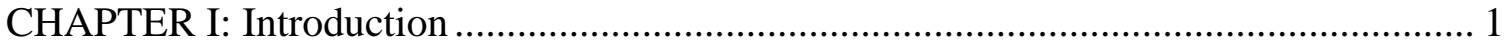

Purpose of Study ........................................................................................... 3

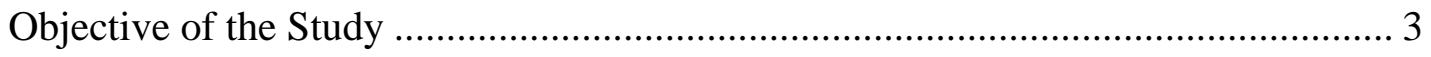

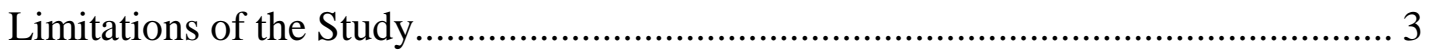

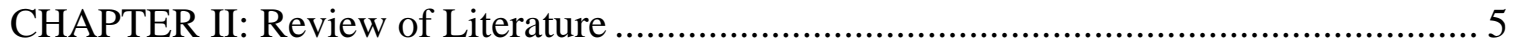

Challenges of Teaching...................................................................................... 5

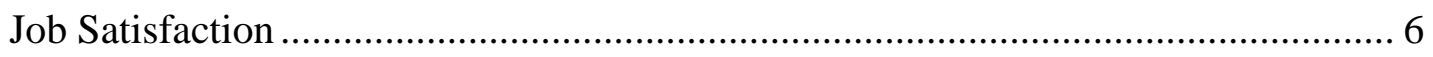

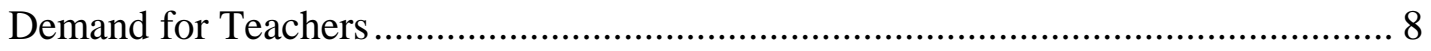

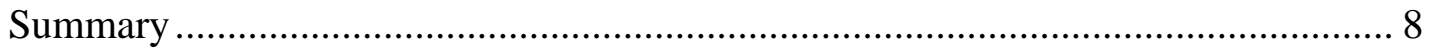

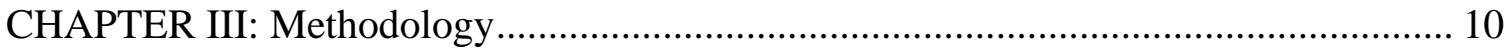

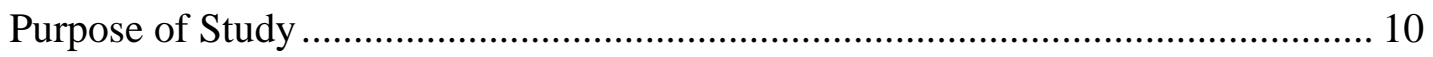

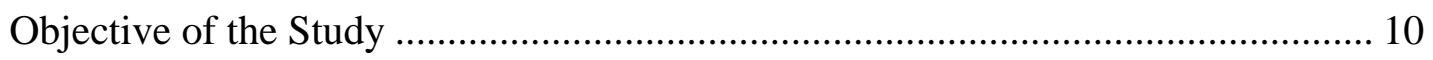

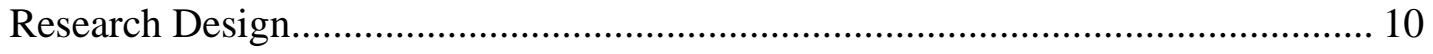

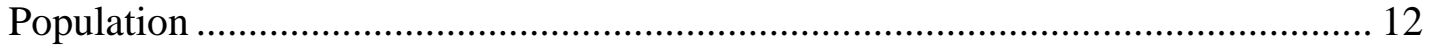

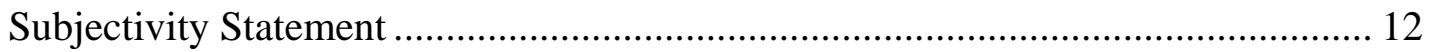




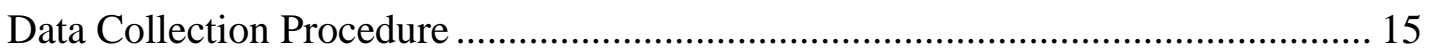

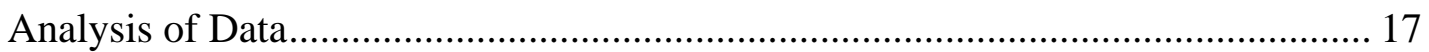

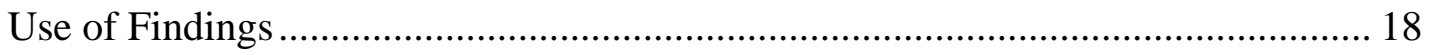

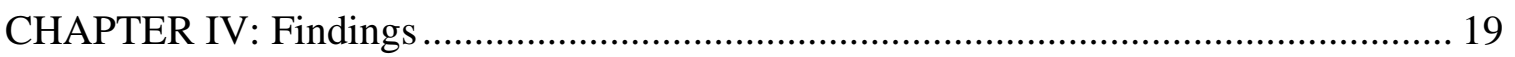

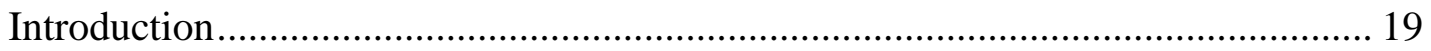

Description of Participants............................................................................... 19

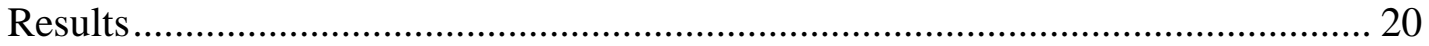

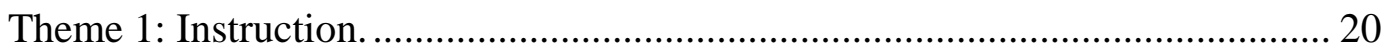

Theme 1a: Classroom instruction. .................................................................... 20

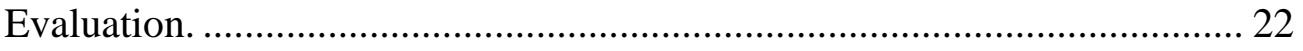

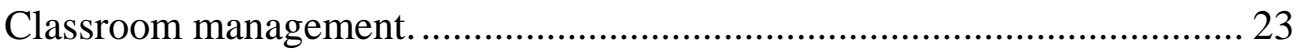

Theme 1b: Laboratory instruction. ............................................................... 25

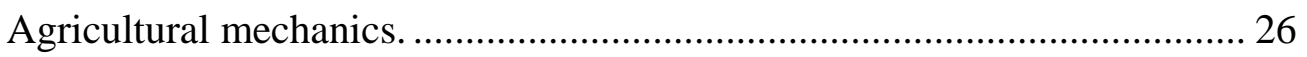

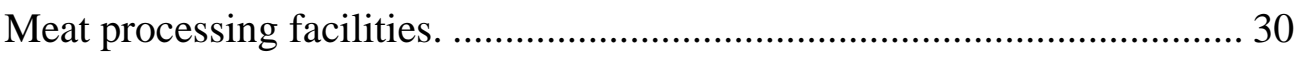

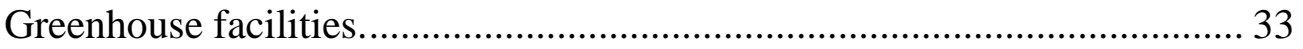

Theme 1c: Adult education............................................................................. 37

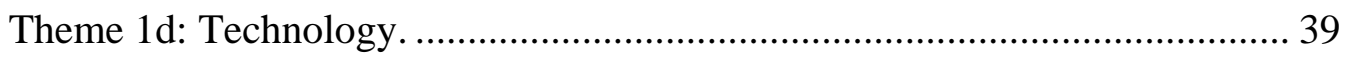

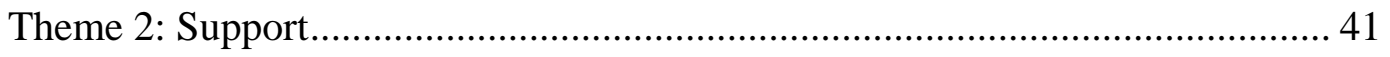

Theme 2a: School administration support. ......................................................... 42

Theme 2b: County administration support. ......................................................... 44 
Theme 2c: State administration support. 48

Theme 2d: Parental support. .................................................................. 50

Theme 2e: Community support. .................................................................. 52

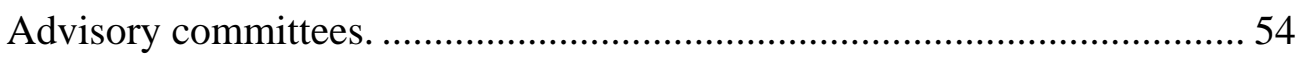

Supervised agricultural experience..................................................... 57

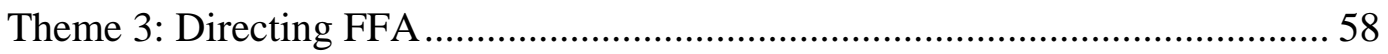

Theme 3a: Importance of supervised agricultural experiences........................ 61

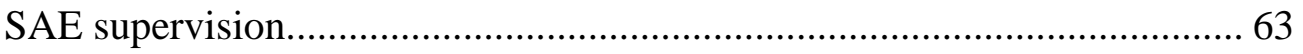

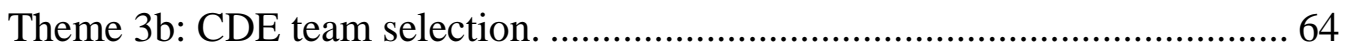

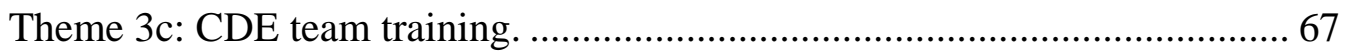

Theme 3d: Success through FFA and CDEs.................................................. 70

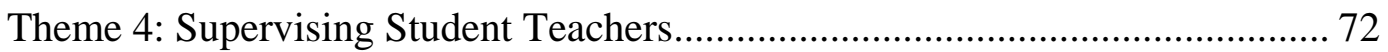

Theme 4a: Feedback and performance. ................................................... 73

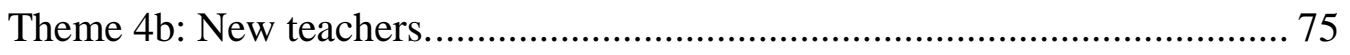

Theme 5: Perceptions of Directing the Total Program ....................................... 76

Theme 5a: Background of teachers........................................................ 77

Theme 5b: Challenges and barriers of teaching......................................... 78

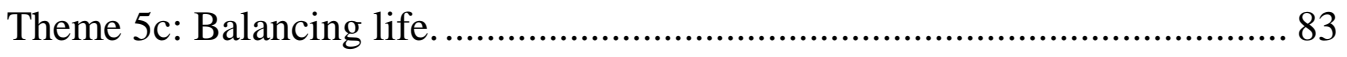

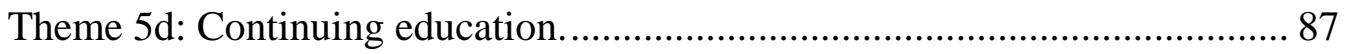

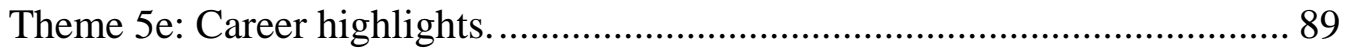




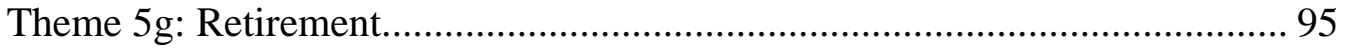

Theme 5h: Future teachers....................................................................... 101

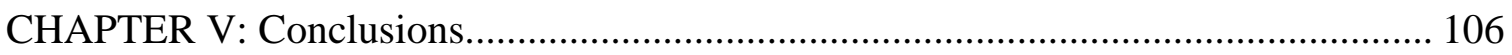

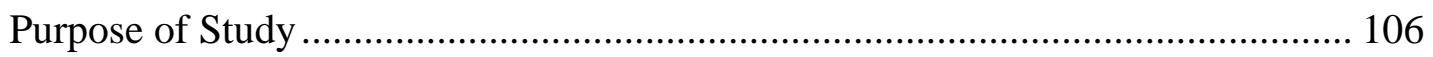

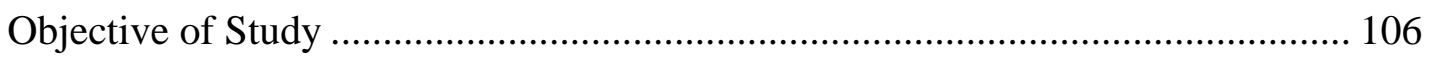

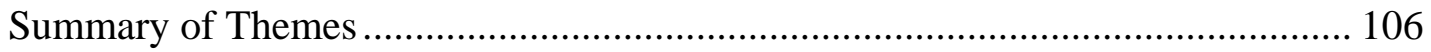

Conclusions from Themes ............................................................................. 107

Theme 1: Instruction ......................................................................... 107

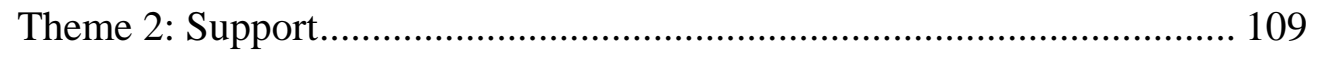

Theme 3: Directing FFA ................................................................ 112

Theme 4: Supervising Student Teachers............................................... 114

Theme 5: Perceptions of Directing the Total Program ............................ 116

Recommendations for Future Research ....................................................... 119

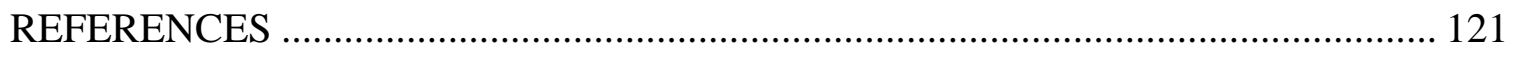

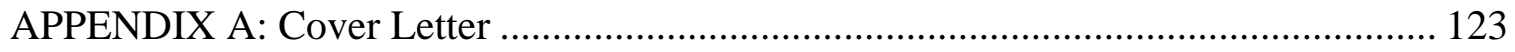

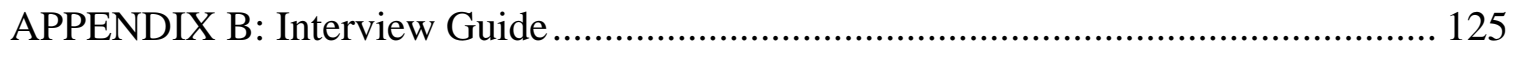

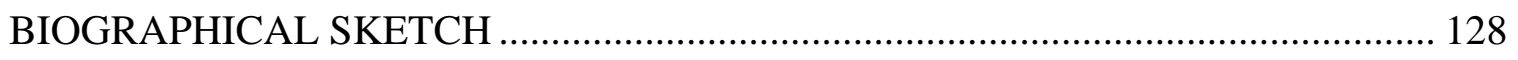




\section{CHAPTER I}

\section{Introduction}

Of all the professions that exist in the world today, education and teaching are some of the most important disciplines. According to educational reformist John Dewey (1916), "Education, in its broadest sense, is the means of this social continuity of life” (p. 162). Without education and teachers, society as a whole cannot advance (Dewey, 1916). Without this advancement, new and old information cannot be disseminated and therefore a lapse of knowledge occurs. As with any profession, challenges often occur and teaching is no exception. In order to advance education and the art of teaching, one must have a perspective of the challenges an individual faces in the teaching profession and be able to have the necessary and pertinent skills to reduce those challenges in order to increase teacher efficacy. Although we often look at the challenges first-year teacher's experience, research has not shown the perspective of challenges and successes of teaching from a retired teacher's perspective.

According to Mundt and Connors (1999), agriculture teachers face multiple challenges during their teaching. Some of these challenges include activities surrounding the FFA chapter; student experience programs; establishing and building support with other faculty, administrators, and community leaders; personal and professional responsibilities; motivating students and discipline; classroom management; and facility maintenance. Although Mundt and Connors’ study was representative for the first years of one's teaching career, the literature suggests that it was consistent of those who were in the post-emergent stages of their career. Other challenges and barriers faced in 
agricultural education outside of the classroom include gender, family relationships, home location, and ability to relocate for other opportunities (Rocca \& Washburn, 2008). In the past years, West Virginia has experienced a consistent rate of agriculture educators who retire from the profession. Within the 2013-2014 school years, West Virginia experienced five retirees within agricultural education (Boone, 2014). According to Kantrovich's (2007), national study of the supply and demand for teachers of agricultural education from 2004-2006, the rate of retiring agriculture educators is exponentially increasing thus, resulting in the demand for new teachers to fill these positions. One could easily attribute this rise of retirees to those teachers who were born during the "baby boomer” (1946-1964) and early "generation x” (1965-1980) eras. According to Odell, Soloninka, Lawrence and Gartin (1992), the average West Virginia retired secondary agriculture educator taught agriculture for 32 years. Furthermore, they found that those retired educators retired around the age of 62 .

Since the average agriculture teacher in West Virginia serves approximately 32 years in the profession (Odell et al., 1992), it was noted that they spent a great deal of time in and around the classroom. By nature, they have been at some point in their career, a pre-service teacher, a beginning in-service teacher and tenured in-service teacher. What possibly could the voice of the retired agricultural educators reveal? What makes them so unique? The viewpoint is simply the extended span of time. With an average of three decades in the classroom, they hold a unique perspective of the profession from a careerlong historical standpoint. According to Stephens (2001), the average teaching career in the United States has dropped to eleven years. With West Virginia agricultural educators' 
mean career length two decades the senior of the national average, their views could provide an insightful yet distinctive perspective to the study.

\section{Purpose of Study}

The purpose of this study was to determine retired secondary agriculture educators' perceptions on the various challenges, barriers, as well as successes and satisfaction of teaching high school agriculture in West Virginia.

\section{Objective of the Study}

The objectives of the study are reflected in the following research questions which were used to guide the study.

1. What memorable experiences were present in directing a total agricultural education program?

2. What career highlights were present in directing the total agricultural education program?

3. What challenges and/or barriers were present while directing the total agricultural education program?

4. What was the career satisfaction after retiring from directing the total agricultural education program?

\section{Limitations of the Study}

The study was limited to secondary agricultural education instructors in West Virginia who retired from the profession within the past ten years because at the time of this study, there were no retired individuals who solely taught in the middle school 
setting. In addition, this study only incorporates a male population because at the time of this study, there are no retired female agriculture instructors in West Virginia. 


\section{CHAPTER II}

\section{Review of Literature}

\section{Challenges of Teaching}

Within the agricultural education profession, there are a variety of factors that pose as challenges to one's career. Although there is a great deal of emphasis placed on the actual classroom and program challenges, a variety of external factors present a much more different challenge for those who teach. It is important to address these challenges and issues to help new teachers as well as seasoned professionals cope and ultimately promote teacher efficacy (Mundt, 1999).

According to Mundt \& Connors (1999), most first year teachers experience great challenges with classroom management and student discipline. In addition, factors that extended beyond the classroom but remained within the scope of the total agricultural program duties such as organizational management, FFA chapter activities, SAE supervision, as well as personal and professional time management arose as great problems and challenges. Within the total agriculture program, FFA and its activities represent only a small percentage opposed to classroom and laboratory instruction. However, FFA activities such as effective alumni chapter organization, advisory committee management, organization and planning of activities as well chapter member recruitment and retention have showed to be a large percentage of the problems and challenges beginning teachers face (Myers, Dyer \& Washburn, 2005). Although these findings are very apparent within the profession, those challenges within the scope and duty of teaching showed to have little effect on career decisions of pre-service teachers who are preparing to enter the profession (Rocca \& Washburn, 2008). 
Within the agricultural educational profession, there are a plethora of external factors that are representative of the challenges and/or barriers that both new and veteran teachers face. External factors such as financial compensation, time management, paperwork, home and school time balancing, school administration as well as facility and equipment availability were found to be challenges faced during one's teaching career in West Virginia (Boone \& Boone, 2009). Another somewhat external challenge factor within agricultural education is supervision and interaction from administration. Agriculture teachers have a desire to involve their administrators which includes principals, directors and counselors within their programs. They want to develop positive professional relationships with administration to enhance feedback, validation, constructive criticism which in return develops administration's understanding and support of the total agriculture program. The desire to meet these goals is often inhibited due to lack of support and visibility from administration which presents another unique challenge agriculture educators face (Paulsen \& Martin, 2014).

\section{Job Satisfaction}

In the past, one of the most motivating factors for retaining teachers is overall job satisfaction. If one is satisfied with his/her career, the more likely that he/she is to continue said career and ultimately retire from that profession. For many, one's profession, especially in agricultural education is a great professional and personal investment. Not only is a teacher an individual that facilitates learning, they are also a learner. One of the greatest tools an educator can use as a learner is overall collaboration with other teachers and administrators (De Lay \& Washburn, 2013). 
A great deal of emphasis concerning job satisfaction also relates to personal matters within the profession. Such factors include achievement, advancement, recognition, total responsibility and the actual work. On the contrary, the negative aspects of job satisfaction focus more on the technical aspects of teaching such as interpersonal relationships, administration, compensation, working conditions and supervision. The most negative aspects of the job found by Ohio agriculture educators in 1999 were school administration (principals) and local school boards (Castillo \& Cano, 1999).

With respect to gender related to job satisfaction, Cano and Miller (1992), found that male and female agriculture educators do not differ greatly in perception of job satisfaction. However, they found that one's current position, years in the profession and highest degree status didn't significantly affect an individual's overall job satisfaction regardless of gender. Another contemporary issue facing the agricultural education profession with respect to efficacy and satisfaction is means of certification. Due to a higher demand for agriculture teachers and the lack of available traditionally certified teachers, the growing trend within the profession has shifted to alternative certification endeavors. Although this trend has increased, the relationship of certification method to efficacy and ultimately job satisfaction has little to no effect (Rocca \& Washburn, 2006).

With the average agriculture educator retiring between the ages of 55-65, they are spending a great deal of their life in the classroom. Due to West Virginia's consolidated teacher retirement system, one must have a certain number of years served in addition to their age to be considered for retirement. Most retirees today have worked at least thirty years in the teaching profession. In West Virginia, the average retired secondary agriculture teachers taught for 32 years and retired around the age of 62 (Odell et al., 
1992). Croom (2003) suggests that as agriculture teachers advance in age and experience, they are more likely to “burnout” or experience a great deal of mental and emotional exhaustion. In correlation, Brouwers \& Tomic (2000) further suggest that once emotional and mental fatigue advance, teacher's performance greatly suffers. This phenomenon of “burnout” may have a great impact on one’s decision to retire early or retire as soon as one becomes eligible.

\section{Demand for Teachers}

As with any profession, retirement of the workforce leads to a demand to fill vacant positions. In recent years, West Virginia has experienced a somewhat steady rate of retirement among agriculture educators statewide. In the past two school years, five agriculture educators retired from the profession in West Virginia. Nationwide, the demand for agriculture educators is exponentially increasing due to retiring educators, those who left the profession and the creation of new programs (Kantrovich, 2007). With the average agriculture teacher in West Virginia retiring around the age of 62 (Odell et al., 1992), those teachers from the "baby boomer" generation will represent the majority population of current and near age retirees.

\section{Summary}

While beginning and tenured in-service agriculture educators differ greatly in experience, education and age, most are facing shared challenges of teaching. Both groups experience issues within the scope of teaching, working with administrators and external factor such as pay and balancing work and life (Boone \& Boone, 2009). Within agriculture education, several factors are greatly linked to job satisfaction which in return 
leads to continuance within the profession. Job satisfaction along with mental and emotional exhaustion also referred to as "burnout" are contributing themes within the profession. With the demand for agriculture teachers nationwide on the rise due to retirement, attrition and new program formation, a great number of teachers will be needed to fill those positions (Kantrovich, 2007). 


\section{CHAPTER III}

\section{Methodology}

\section{Purpose of Study}

The purpose of this study was to determine retired secondary agriculture educators’ perceptions on the various challenges, barriers, as well as successes and satisfaction of teaching high school agriculture in West Virginia.

\section{Objective of the Study}

The objectives of the study are reflected in the following research questions which were used to guide the study.

1. What memorable experiences were present in directing a total agricultural education program?

2. What career highlights were present in directing the total agricultural education program?

3. What challenges and/or barriers were present while directing the total agricultural education program?

4. What was the career satisfaction after retiring from directing the total agricultural education program?

\section{Research Design}

For this study, a qualitative research design was selected to obtain data.

Qualitative research “studies human experience holistically, taking into account a broad range of factors and influences in a given situation” (p. 451) (Ary, et al., 2014). This 
design is best utilized because it allows for deep reflection on responses to get the best picture of the problem or success without being narrowly restricted and limited.

In order to capture the desired full-reflection in the study, in-depth face-to-face interviews were used to obtain the data in this study. By soliciting experiences through stories and interaction, the research becomes more personal and allows for the researcher to further investigate underlying themes that unfold during an interview. In addition, Seidman (2013) found that interviewing was a basic mode of inquiry and held that "recounting narratives of experience has been the major way throughout recorded history humans have made sense of their experience” (p.8). Furthermore, Seidman (2013) defined the root of in-depth interviewing as "an interest in understanding the lived experience of other people and the meaning they make of that experience” (p.9). This method of research allows the researcher to retreat from their own ego and motives and allows the embodiment of the research to exemplify the worth and importance of others' experiences.

Within interview-based research, there are multiple methods which can be used to obtain data. This research study implemented the use of semi-structured or in-depth interviews to complete that task. This method is open-ended but is governed by a general script or interview guide, and can cover a plethora of topics. According to Bernard (2006) this type of research allows the interviewer to maintain discretion to follow leads within the interview via probing follow-up questions or "probes.” In addition, Bernard (2006) defines probing as "stimulating a respondent to produce more information, without injecting yourself (the researcher) so much into the interaction that you only get a reflection of yourself in the data” (p. 211). 


\section{Population}

Dooley (2007), described qualitative sampling as “emergent and not set a priori” (p. 36). The target population for this study consisted of retired agriculture educators from West Virginia. A potential list of subjects were derived from the West Virginia University Agricultural Education teacher database. From that list, the final participant pool was refined using multiple factors. To establish a variety of backgrounds, experience in the form of single and multiple teacher departments as well as middle and/or high school levels taught were examined. In addition, to gain a broad spectrum of time, beginning of teaching service decades of 1960, 1970, and 1980 were used. After refining and determining the list of potential participants, participants from each decade were drawn by random assignment to establish the final participant list. In this study, one teacher was utilized from the 1960's, three from the 1970's and one from the 1980's. In addition, one of the participants taught only in single teacher department, whereas the remaining four participants had taught in a multiple teacher department at some point during their careers.

\section{Subjectivity Statement}

Growing up in rural West Virginia, I have had the great pleasure of being reared on a three-generation family farm. From an early age, I have been involved in agriculture and possess an inborn fondness for this very important industry. My first active adventure with agriculture took place when my sibling joined the local 4- $\mathrm{H}$ club and began raising heifers. Soon after, I joined the very same 4-H club and started the very same special heifer project. I continued my experience and expanded to raising sheep, feeder calves 
and market hogs for show and sale at the local county fair. Little did I know that 15 years later my first exposure to agriculture would help me establish the knowledge and skills to start my own herd of cattle which I still manage today.

As a freshman in high school, I found myself in an agricultural education class, and a member of the FFA. This year was pivotal in determining and focusing my goals for the future. My introductory training in agricultural education and involvement with my SAE and the FFA allowed me to expand my knowledge of agriculture, develop leadership skills, and further develop my agriculture enterprise. At the heart of my experience, was my agriculture teacher, whom I became very fond of and established a firm working relationship. His direction and guidance would prove very instrumental in my success that eventually lead to earning both my State and American FFA degrees. In addition, his guidance and persistence helped develop and solidify my goal of pursuing a career as an agriculture educator.

During my undergraduate studies, my passion and drive for agriculture as well of wanting to educate others about the industry developed and I found myself deeply engaged as a young professional. As an undergraduate student in agricultural and extension education, I gained a unique perspective of agricultural education and the profession on the national, state, and local levels like never before. It wasn’t until preparing for my student teaching semester, that I found myself facing similar issues as those individuals currently teaching in the field. The transition of student to teacher while still being a student was very challenging, but I found sense of purpose and heightened responsibility as my student teaching experience transpired. As a student teacher actively 
teaching in the field, I experienced a host of highlights, challenges, and barriers that added to the reality of directing and operating a total agricultural education program. As I began my Master of Science program, I reflected upon my student teaching opportunity and dissected the highlights, challenges, and barriers as well as overall satisfaction of my experience in that capacity. I found myself in deep thought about not only the classroom delivery, but organizing and directing both FFA and Supervised Agricultural Experience programs. Not only did it give me an opportunity to critique myself, but it allowed me to look at all the factors surrounding the experience and the influence they had on the outcome. It left me with a pondering question, “Why don’t we as a profession, formalize the commencement and reflect back after our experience or career as an educator and director of a total agricultural education program has ended?” That very provoking question has lead me to further investigate this formalization process and prompted my interest in conducting this study.

Since this research study is based on West Virginia agricultural education programs, which I have been involved with in some capacity for over 10 years, I inherently possessed certain biases during the course of this study. Unlike in a quantitative study, I know exactly who the research participants are and will be able to connect them to their responses, although I am ethically bound to keep confidential in the analysis phase. Over the span of my involvement in agricultural education, I distantly know the majority of the participants, their backgrounds, teaching environments, what their programs consisted of and their involvement in the state agricultural education scene. In addition, to knowing the participants and part of their background, my 
involvement in both teaching high school agriculture and at the post-secondary level has exposed me to congruent experiences of those participating in this research study.

\section{Data Collection Procedure}

Data for this study were collected through conducting face-to-face, in-depth interviews using a guiding script which outlined the purpose of the research study, and main questions with potential probing follow-up questions. The interviews were mainly guided by the overall research questions but were semi-structured in nature to allow the researcher to discover potential new ideas or allow for probing follow-up questions to further investigate aspects of questions (Bernard, 2006). The letter of solicitation as well as the guiding script was submitted and approved by the WVU Institutional Review Board. All interviews were audio recorded with permission granted by the research subject. In addition to the recordings, field notes were collected during the interview. A reflection with each participant took place at the conclusion of the interview in order to ensure proper interpretation by the researcher. From that reflection, additional notes were taken and responses were further clarified immediately following each interview as a form of member checking (Patton, 2002). After all interviews were completed, recordings were transcribed verbatim via third-party transcription service. Following transcription, each subject's responses were delivered to them to confirm the information contained was a true and accurate representation of the information they provided.

In order to ensure trustworthiness and rigor within the study, the researcher had the responsibility to establish the following tests: credibility, transferability, dependability, and confirmability (Lincoln \& Guba, 1985). As quantitative research is concerned with establishing internal validity, qualitative research methods must 
implement a very similar method, credibility. Lincoln and Guba (1985) held that to ensure credibility in qualitative research, the data derived from the participants must be accurately portrayed and described at the analysis phase of the study. The researcher established credibility using the following methods:

1. Member checks: following transcription, the analyzed data was presented to the participant to confirm that their responses were accurately described.

2. Peer debriefing: a researcher not connected to the study was utilized to ensure proper use of analysis methods.

3. Persistent observation: the researcher ensured that all the face-to-face interviews were managed in an in-depth manner by using the approved guiding script and interviewing techniques.

4. Referential adequacy materials: written documents and field notes were examined in order to verify and yield a holistic perspective of the observed interview.

5. Triangulation: data collection methods were implemented by the researcher to establish data authentication. Data evidence found through the interviews and journaling was the primary source to establish triangulation.

The subject of transferability in qualitative research is comparable to that of external validity in quantitative methodology. Transferability establishes that the result or outcome of a qualitative study can be used by other researchers in similar situations (Lincoln \& Guba, 1985). Although used in traditional methodology, generalizability is not adequate in qualitative methodology because research subjects will never be the same (Dooley, 2007). 
Dependability is comparable to the highly important requirement of reliability in quantitative research models (Lincoln \& Guba, 1985). Lincoln and Guba (1985) found the contexts within qualitative research study evolves and placed great emphasis on the responsibility of the researcher to account for the changes which take place in the research environment. Dooley (2007) stated that to ensure dependability, the researcher should "track the process by providing an audit trail (dependability audit) with documentation on methodological decisions and reflections” (p. 39). This was accomplished through in-depth journaling.

The final test of trustworthiness and rigor as stated by Lincoln and Guba (1985) is confirmability. Lincoln and Guba (1985) refers to the extent of corroboration or confirmation of results by others as confirmability. As previously stated under the test of dependability, Lincoln and Guba (1985) as well as Dooley (2007), recognized the researcher has the burden to describe or detail changes that materialized in the research environment and report how the particular changes affect the methodological aspect of the study. They suggest once again, furnishing documentation via audit trail, of any methodological decisions and reflections that transpired and their implication, if any, on the causatum of the study.

\section{Analysis of Data}

Analytical methodology for qualitative research was first introduced by Glaser (1965) and established methodology in which theories could be developed from qualitative data. This technique secures simultaneous analysis across contrastive cases and samples (Glaser, 1965). This study implemented Glaser and Strauss' (1967) four-step constant comparative method. This methodology implements a comparison of multiple 
cases within a study barring evolution of theory and relationships (Glaser \& Strauss, 1967). The four-step constant comparative method is comprised of the following elements: 1. comparison of incidents applicable to each category, 2. integration of categories and their properties, 3. delimitation of theory, and 4. writing the theory. The researcher employed the constant comparative method elements as follows:

1. Comparison of incidents applicable to each category: Categories for each case were created from occurrences described by the data. The categories were used to develop common themes and rules were established to govern data incorporation.

2. Category and property integration: Categories established in the initial phase were analyzed. After analysis, established categories were further combined, refined or reformed into a sub-category.

3. Delimitation of theory: As analysis progressed and theme categories became more delineated, categories were integrated.

4. Composition of theory: Member checks of data were confirmed and the final manuscript was composed.

\section{Use of Findings}

The results of this study will be utilized by state educational administration, state supervisors of agricultural education and teacher educators to determine areas of the agriculture teaching profession which need to be changed or possibly strengthened to enhance teacher and program effectiveness. 


\section{CHAPTER IV}

\section{Findings}

\section{Introduction}

This chapter presents the findings obtained through the data collection, and analysis processes. A summary of thematic results is presented within this chapter. The findings address the research questions which guided the study as follows:

1. What memorable experiences were present in directing a total agricultural education program?

2. What career highlights were present in directing a total agricultural education program?

3. What challenges and/or barriers were present in directing a total program?

4. What was the career satisfaction after retiring from directing a total agricultural education program?

\section{Description of Participants}

In order to ensure anonymity, participant's names were removed and replaced with pseudonyms. Participants were assigned a letter code (ABCDE) according to the order in which the interviews took place. From the preliminary coding, fictitious names were developed as follows: Arthur, Barry, Charlie, Dennis, and Edward. 


\section{Results}

Theme 1: Instruction. The first theme established from the data was instruction. The instruction theme incorporated multiple specific factors derived from the participants. The participants discussed these factors throughout the formal interview process. During the interviews, these factors were also supported by the researcher's observations of the participant's body language. The identified factors included: classroom instruction, laboratory instruction, adult education, and technology.

Theme 1a: Classroom instruction. Within the total agricultural education program, classroom instruction was perceived to be the core standard in which all other facets of the total program stem from. Classroom instruction entails laying the groundwork or base knowledge from which specialized skills and training are derived (ABCDE). During the discussion, it was noted that over the span of the participant's careers, agricultural education curriculum has evolved from being solely science based to a more, practical, and skill based application of agricultural science. Charlie stated, “Now, it is more real.” Arthur noted, “Things have changed from a need-to-know basis to a more practical sense of applying the general concepts. Some people are more scientific in nature, whereas many students now are more practically inclined thinkers.” He described the change in curriculum by stating,

It's not just farming anymore, it's not just pigs or cows. Its farming but, it's a whole different thing. It's what you want it to be. It can be as basic or as scientific. It's more focused around the individual needs of the students. So, if some kids want to get into genetics, we steer them into that direction and learn the concepts, and then engineer the experiments. To me, it’s more individualized. 
Also, you have to maintain a curriculum that teaches students a skill for when they graduate and are in the real-world.

Edward stated,

Well, this is extremely important because we have an opportunity to teach students skills that they need in their adult life. We work at it very religiously so that they understand that you do things honestly. And so, these are life-long skills that they can take with them into the future after they graduate from high school. In addition to a strong skills based curriculum, it was noted that there are a few challenges when maintaining and developing the direction of classroom curriculum. Barry noted,

I think the true challenge for a teacher is try to keep your curriculum beefed up enough so that when kids come out of the program, they have the skills that the job market is looking. In addition, you have to steer the curriculum in a direction that is keeping up with the times, while still keeping in mind what they need to have to be successful later in life.

Edward stated,

With respect to the curriculum and delivery, students now would rather see things than hear things. We can't do away with all of that, but we must understand that our kids are very visually inclined today. They'd like to see things in this part and it is more interesting to them. There's no doubt about that. And so to those who are the future of the profession, don't be afraid to change, because we must adapt to their needs and the needs of the greater community. 
Evaluation. During the interviews, the teachers were adamant that an important and challenging part of the classroom portion of their programs was evaluation of students. Teachers are not only responsible for instruction, but evaluating and grading students in both classroom and laboratory settings. Barry noted, "One of the hardest things for a teacher to do sometimes is evaluate students. Everyone has different skills and abilities and sometimes that's hard to quantify with a grade. I guess I got better at it as time went on.” Dennis added, “There's two grades, A or F, that's the way it is in life. You either pass, or you don't.” Arthur shared his philosophy on evaluation, I guess I shared the philosophy of many before me that you just don't fail a student. There shouldn't be anyone failing in your class. The easiest thing to do is to fail them. You have to find out what they like, what they may have an interest in and capitalize on that. Then you will find that the easiest thing isn't failing them, but evaluating them on what is best for them. However, that philosophy changed with time because throughout my career, the kids changed and I had to change with them.

It was noted that over time, overall student attitude towards school changed drastically. With respect to the change, many of the teachers agreed that their policies on evaluation changed as well which presented a challenge to them. Dennis stated, It used to be that they would fight for their grade. Later on, that changed and you had to call a spade a spade and not think twice about it. You didn’t want to fail someone, but you pushed them until they couldn’t be pushed no more. 
Arthur added,

Later on in my career, teaching as whole got difficult because of the students. In return, that made evaluation a bit more difficult as well. I ended up failing kids, because they didn't want to do anything. When I went to school, everybody worked for a C, or worked for the grade. But now, it's a little different. But I did fail kids in my latter years. Not good kids, but those who just didn’t want to be there. And we got that straight, we don't want to, that's fine. I would actually make them sign a paper every day that said, “I don’t want to do anything today,” and I'd sign it. And then we'd do the discipline game and go through the proper channels.

Classroom management. The teachers in this study recognized that discipline was an important factor of classroom instruction and management. In addition, the agriculture teachers were adamant that discipline was a constant battle but was easily combated by setting and demonstrating expectations. Dennis stated,

At times, there was a real struggle there. If you had a good Ag student, then there was no problems. But if a student had you for an elective or something, it wasn't always the same. I had a young lady call me every name but a white man and I had to stand there and take it.

Charlie added, I really think it's just, it all boils down to expectations. I was always honest from the beginning as to what I expected of them. Over time, their vocabulary has gotten a little bit harsher, but all in all, kids haven’t changed much. They knew my expectations and we got along well. 
It was noted discipline had changed from the beginning to the end of their careers. The teachers identified a pivotal change in the student populous with regards to discipline. Edward stated,

Kids are different today. They sure are. This thing that coming from broken homes really bothered me and we're not going to correct it. It seems to me we can't correct it, but those kids are kids that really need help. They really need help with respect, accepting responsibility and following directions. Most of the kids have social problems. Very short-fused, so to speak and sort of walk on the edge of the cliff, and so, we have to quickly recognize those kids and help them. They need help. But we are in an era where some kids are ornery, but there's also a few that can be extremely dangerous. And that scares me so [sic].

When asked to identify when the change happened, Dennis commented, I saw that change with students and discipline when the parental units started becoming one instead of two. When I started, everyone had a mom and dad at home. Later on, divorces were prevalent and many of my kids only had one or the other at home or a split situation. You could almost always tell whose parents had split solely on the discipline problems of the student.

It was noted as a whole, discipline in the agricultural education program is a challenge for teachers. Edward noted, “Discipline issues have driven people out of the teaching profession, no doubt about it. Let's face it, there are some people who just can't control kids because it's so challenging." When asked about how to combat discipline problems in the classroom, Charlie stated, 
A teacher has what they would like to think as assumed power and that's about all it is. They [students] have to give you the opportunity to have power over them, and if that doesn't happen, that relevant power, it has to be earned. And once you gain them, you can only befriend them so long and they've got to know what you expect, and it takes a little while to develop that repertoire.

Edward added,

I think if you establish respect early, you can’t let it get away from you. If you establish it early, which I was able to do so, and then when kids start becoming a success in your program, that builds respect. But respect, the quicker we do that, we can head off problems. You never know who is coming here this morning that may have had to, I'll use the words "fight for their breakfast at home.” That's the kind of kids you have to be careful with. But we have to be able to handle discipline based upon the fact that we care for one another.

Theme 1b: Laboratory instruction. Throughout the interviews it became apparent that laboratory instruction was an important part of the curriculum in the teacher's programs. Common laboratory settings in the participant's programs included agriculture mechanics, meats and animal processing facilities, and greenhouses. Barry noted, "Laboratory settings are important because it gives the students an opportunity to take the classroom portion and bookwork and actually see that unfold before your eyes. Labs turn concepts into skills.” Edward added, “There’s a lot of finesse that goes into organizing a class for a laboratory situation. But the return that the students get from the experience is monumental.” Teachers identified laboratory settings as important environments for learning which in return can also double as a source of fundraising for the program. 
Charlie noted, "Labs help strengthen the total program because you can show that they are learning, while at the same time making money. That helps show administration that you are self-sustaining.” Laboratories also add elemental challenges to the teacher and their duties. Edward stated, "Everything you add becomes also a restraint upon your time. That can be challenging. But I think as you look at that, you can control that. You must control that or it will get out of hand very quickly.” He further added, More facilities equals more time you have to spend with the program. With the meats lab or greenhouses, extremely time-consuming and it is something that does not stop at the end of the school day [sic]. If you want to be successful [sic]. And so, I think that was the biggest challenge that ever faced me. There were days when, even though you get students to help you clean up the meats lab or greenhouse, you may not be getting home till 6 o'clock in the evening. Which is two and a half hours after everyone in the building has went [sic] home for the day.

Agricultural mechanics. Agricultural mechanics laboratories or "shops” were a common lab setting in each of the participant's programs. Skills taught in the mechanics labs included woodworking, electricity, building construction, tool conditioning, plumbing, masonry, hydraulics, agricultural engineering, welding and fabrication. Arthur noted, "Skills taught in the shop were extremely important because if you are involved in agriculture, the value of saving money by knowing mechanics and being able to fix something yourself [sic] is extremely valuable.” Dennis noted, "Even teaching the basic tools from their uses to terminology was extremely valuable. Those are things they are 
going to use later in life, and will have a better appreciation for them later on.” Arthur added,

We are living in the 'let's just buy a new one' society. Mechanics help combat that way of thinking. I once needed to work on a grinder wheel and asked the kids for the wheel dresser and they just replied 'why don’t we just buy a new one.' So, I think by showing them the value of fixing something yourself opposed to just buying a new one unless you absolutely have to, you instill a value of economics and ability to perform valuable skills.

He further stated, "I used to have farmers bring their tractors in and we would complete all the maintenance on them. They would change the oil, check the batteries and such. I brought the real world to them, and unfortunately they don’t do that anymore.” Barry noted that skills taught in the mechanics laboratory settings can have a great impact on careers after school. He stated,

I had a student who loved to TIG weld and told me, 'I want to be a TIG welder.' Luckily for him, he was on a mechanics team that went to Kansas City, and in the large area, found a TIG welding school in Tulsa, Oklahoma. He came back to me and said, 'I'm going to Tulsa and become a certified TIG welder' and so that's what he did. I also had a student who came to me because I had a couple metal lathes in the shop. They told me, 'I'd really like to learn how to run a metal lathe.' So I taught him the basics of machining metal. Didn’t make him a machinist by any means, but that's what he wanted. He graduated, went to James Rumsey, went through their machinist program and still works today at Luke Mill as a 
machinist. We don't think that a simple skill like that can turn into a full blown career.

Agriculture mechanics laboratories also give students the opportunity to further their skills and transform them into certifications. If agriculture teachers obtain certain credentials, they can certify students in area such as welding (B). It was noted that the ability to have a graduate of the agriculture program who finished with a specialized certification was a highly important aspect of being a productive and successful total program. Barry stated,

I think that it's highly beneficial to certify students in a specialized skill or program as an agriculture teacher. We circumvented that a little bit because I technically wasn’t a certified welder, I couldn’t certify students in welding. I had a good working relationship with the certified welding teacher who could do the certification. If I had a student, that was their goal, they wanted to be a certified welder, I'd teach my unit and the welding instructor would test them for me. He would bring them over there, run them through a certified welding test and if they passed, would certify them. We should be able to certify students in the program in welding and electricity with absolutely no problems.

It was noted that proper facilities and equipment were important components of a successful agriculture mechanics laboratory. Barry noted, I was never bashful about asking for something. But I was fortunate too, probably, to have one of the best equipped agriculture mechanics shops in the state. I still think it's very well equipped. But back then, I think that's why our students were successful at competitions and things, because we did have good equipment. In a 
lot of cases, we had more equipment than the university had. In fact, I visited a lot of factories and saw if they had a particular piece of equipment, I'd try to get piece of equipment in the shop so my students knew how to adjust and properly use that machine before they applied for a job where they would have to use it. You just tried to get whatever piece of equipment that the local companies were using in your shop, and do so quickly.

Maintaining proper facilities and equipment through funding can be a challenge to the agriculture teacher (ABCE). When Charlie started teaching, he had to revitalize the equipment and found it challenging to do so. He stated, When I changed schools during the early years, I left a super classroom to 24 chairs sitting in the middle of the shop floor and no classroom. I went to a shop that was furnished with probably World War II surplus, and every cabinet that you opened up was full of things that the government had given away 50 years ago. That's probably the last time they'd ever been seen. So, updating things was a true challenge.

Barry noted that outside funding was key to keeping an up-to-date shop. He stated, Well, back then, property program modernization grants were about the only way you could squeeze your administrator with some Perkins funding that they had. They had many options with Perkins funding and unfortunately I didn’t find that out till later. But that's basically what you did. You worked with your principal, your director, and if he needed some data so that he could write a program modernization grant, or you could write one, and say, "Hey, this is what we need.” That's how you went about doing it. You just put equipment requests in 
every year knowing that there is never enough funding to go around. Sometimes, if you were lucky, the squeaky wheel would get the grease.

Meat processing facilities. During the interviews, it was noted that each of the teachers had a meats processing facility/ laboratory in their programs. This laboratory setting is somewhat unique to the state and it was noted that it plays a large role in not only the curriculum but SAEs and FFA as well. Edward noted, "There are not many states that even have a meats program. But I think it’s a long-lasting thing, because there’s a consumer knowledge that is very important.” Charlie added,

The reason why I decided to have a meats facility was not to do hams and bacons, but to train meat cutters. I wanted a kid that could go out and if he needed to, when he graduated, he'd go to work. And that was my goal. They could go work for someone else, or open up a little custom processing facility here; at least do deer, or whatever.

Edward stated,

Even though the meats lab was typically an upper level experience, I tried to give all of my classes an opportunity to work and experience the meats lab. We're looking at probably four weeks where they learn the safety measures, safety practices, first of all. They would learn how to operate the machines that we had, then how to keep things clean. This gave them a good, fundamental start. Then the upper level classes would be the ones who would actually process the meat. Within the meats and processing laboratory, it was noted that the facilities were restricted from slaughtering and only allowed to process animals. In addition, the facilities had restrictions on the amount of processing of certain animals. Edward noted, "We were 
limited to processing about eight or ten beef carcasses, and lambs. We would also process about 55 of our own hogs and a lot of deer. For our size, it worked perfectly but we wanted custom licensure.”

The meats laboratory also provided opportunities for students and their SAE. It was noted that custom deer processing was a popular method of helping the community, getting students experience, and assisting with SAEs. Edward stated,

During deer processing season, we added the service and processed approximately 140 deer during the two week season. This enabled us to hire students, and this was part of their SAE program. The students were typically experienced upperclassmen. Those were the kids that I liked for deer processing. They had experience, they knew what to do and were very responsible. In addition, I took about four of my eight classes to work on them as well. It worked out beautifully, and was still very legal.

Charlie noted that he operated his meats program and lab very similarly. I thought, "Well hey, these kids need some experience, and we need to make a little money for the lab, so we'll cut up some deer.” Well, there'd never been a deer processing facility in this county, so we took out a little ad in the paper, and I required the students to work 20 hours during the week of Thanksgiving break. They signed a contract on the day they come in and would work from noon until about ten o'clock at night. On the very first day, we took in over 100 deer. I found out very quickly that my prices were too cheap, and that you can only do so much for an education in cutting up deer. It was a good way to get experience and a 
little money for the program. I learned a lot, and they did too. It was a win-win situation for both of us.

Meat and animal processing is a very unique and large aspect of many agricultural education programs in West Virginia. One of the most notable is the Ham and Bacon program. In this program, hog carcasses are processed, cured, smoked, judged and sold at local and state shows. Edward noted,

This program is very valuable because the students got a chance to present to the public a product that we've worked so hard to get. That product must be high quality. It must look good, taste good, smell good, and sell good. And so, there's a tremendous involvement by the student. I also think the program is very important because of consumer knowledge and its importance. The kids must understand and be able to identify cuts of meat and the quality of the meat. The offspring from this, we always had a very competitive meats judging team in the state CDEs. In fact, we were state champions quite a number of times.

He further stated,

The program's number one goal is that it is educational. It's more than simply putting on the table, hams, and bacons. Students must learn, first of all, from the very beginning, how to pick animals that can become competitive, and of course, we did that with our show hogs. There is so much more involved than just the feeding and care of the animals. It's also great because it gets the parents involved. The parents are involved in giving them support, but it must be an educational adventure by the students, or else we just don't let them do it. It became a very economical adventure for our kids and their SAEs. But you have to 
keep control of it, and by doing so we've been able to have a nice, controlled county show in the vicinity of $\$ 60,000$.

The Ham and Bacon program also presents its own set of challenges for the teacher. It was noted that proper facilities and time were among the biggest challenges faced.

Edward stated, "You must have good facilities. You must have good equipment such as a cooler, smoker, slicer, vacuum packer. It can get very expensive.” Charlie added, “It was hard to imagine and actually put into perspective how much time that the program took. You ended up putting more work into it than you did actually teaching. That's why I got away from it.” Dennis stated,

It was a real challenge for me when I started teaching. Back then, everything was done at home, so that meant that you were travelling to homes to do the work. That was stressful. But it was unique because the parents were really involved. Sanitation was one of our biggest challenges and you had to work at it. You also cared for that meat like it was your own child. I'd never done it before and was afraid that they were going to spoil one year. I wasn't going to let that happen so I took hams and bacons home with me. I put them in my bedroom in my house with an air conditioner on a carpet floor of all things. I didn’t know they leaked, or seeped. Well, they did, and all over my carpet. I wasn’t a happy camper at the house, I learned real quickly.

Greenhouse facilities. Finally, it was noted that the greenhouse laboratory was the most important laboratory used by the teachers. Edward noted, "The biggest advantage of the greenhouse is that we can help students become successful in adult life.” The greenhouse is used for both teaching and fundraising purposes. Many teachers rely on the 
funding from the greenhouse to help supplement their programs. Charlie noted, "The greenhouse is a great way for students to get some knowledge, experience, and skills that they will use for the rest of their lives. We all take care of plants at some point in our lives. Edward added, "From learning about plants, to operation and sales, those kids took so much from it and there is so much that we can teach them from it.”

From an educational standpoint, greenhouse laboratories provide a unique learning environment which is required to teach certain aspects of horticulture. Edward noted, "We ran a lot of experiments. We would run germination tests, trouble tomatoes in the off-season and get them to ripen in the winter time. You can't do that in the classroom. It's more than raising plants for sale.” Arthur added, I would find kids who weren’t exactly into plants or raising them. I adjusted slightly so they would end up learning from another angle of the greenhouse through mechanics and maintenance. They would work on the watering systems, fans, heaters, anything mechanical. We often forget that those skills and knowledge set are equally important when running and owning a greenhouse. In addition, the greenhouse laboratory also opened up opportunities to teach students about business. Edward noted, "Since they we were working in there, I taught classes on salesmanship and on the financial part of the greenhouse. It made things come full circle for them.”

One of the biggest challenges of teaching in the greenhouse laboratory setting was evaluation and making sure students were on task. Arthur noted, "Everyone had a task and job to complete. They knew their role, and were expected to complete their tasks for the day. That's the only way to run a greenhouse.” On keeping students on task, Edward 
noted that music was one way to keep them focused and motivated. "We would play the radio in the greenhouse, nothing indecent. That kept them focused and on task. Amazing what a little noise can do for productivity.”

Student evaluation in the greenhouse laboratory setting was noted as another challenge by the agriculture teachers. Students were graded on participation and completion of required tasks. Arthur stated that students had different skill levels which made evaluation difficult. "Everyone had different skills. Some were good at watering, others best at transplanting or selling. Really hard to grade each other differently.” Edward noted,

Yeah, it’s not easy. How do you supervise if they’ve done right? If we're transplanting, and there is a right and wrong way to transplant a flat, we must be productive if we want the finished product on time. And so, when they get it done, they bring it to you and if its not done correctly, you tell them that. You have to adjust this, or get those deeper, or be sure they're all correct. And that becomes an easy evaluation.

During the discussion, it was noted that there were differing opinions and views on how the greenhouse laboratory was operated. Some teachers viewed the laboratory as a teaching-fundraiser greenhouse whereas some expressed their teaching-production views. Edward noted, "We focused on a lot of bedding plants and vegetables because there was the need and demand from the community. So you could say that we were a pretty typical operation.” Arthur stated, “I took the different approach. When you get a little old lady coming through the greenhouse, it throws the whole class off. Mine was production. I found farms that bought everything and they were customers. 
Operating a greenhouse from a straight-forward production standpoint also allows opportunities to spur from just the school setting. Arthur stated, When you operate a school greenhouse as a production operation, you integrate the true agricultural community into your program. The farmers who came in and bought product from us to use on their own operations saw the true value and quality that the students were putting out. They had the opportunity to not only evaluate the plants, but evaluate the students. They would pick out the good students who knew a lot about the product and what went into it, and would turn around and hire those students to work on their own operations. They handled everything from planting, to sales. It was a neat opportunity to actually put the students into the industry as well as get them experience and money for their SAE.

Regardless of the varying methods of operations, it was noted that the teachers treated the greenhouse like a true agricultural business. Arthur stated, "At the end of the day, its not about how many geraniums you raise. It's about how many geraniums you raise and how much money you make. It's a business. It was further noted that an efficient greenhouse should have delegation and duties in order to make the experience as real world as possible. Arthur stated, Each student had a job or title. I had a greenhouse manager that rotated, and they made the decisions and delegated the powers of who was to do what. You can't get more real-life than that. We also used a time clock system. When the time clocks went to computer based, companies would give me theirs. I put them on 
the wall and everyone had a card. Every day they had to clock in and out and if they did, they got a grade. Real-life simulation at its finest.

In addition to operating the greenhouse laboratory as a business from an educational standpoint, it was noted that the greenhouse was also a great opportunity for students to have an SAE. Edward stated,

The extreme value of it also came as we approached sale season which in our area was normally the first part of May. We hired students who would work after school and on Saturdays. This gives students a part of their SAE, which was salesmanship and marketing of crops. We treated the students fairly, we paid them well. There were a lot of days when I would check on them in the morning to get them started in the morning and they would take care of sales during a complete day and I would be back, return back in the afternoon and evening [sic]. They took ownership from the experience and to me, that's extremely valuable.

Theme 1c: Adult education. When discussing adult education in a total agricultural education program, participants were adamant that adult education is a highly important aspect of the total program. They strongly felt that the continuity of education across generations is important to not only better the students, but also the community as a whole. In addition, the participants held that adult education had a huge impact on the total success of a program. With respect to the importance of the adult program, Dennis stated "we've helped the farmers in the area, we've helped the community in the area, we've helped the agricultural economy in the area, and that spread over to the kids, I think it’s viable.” Barry added “If you've got Ag in your county, it’s a must. They 
appreciate what you're helping them with and it pays dividends to not only your program, but you as teacher.”

Adult education within a community is heavily dependent on the needs and desires of the adult learner population. In order to best serve the needs of the community, surveys are a popular instrument to make that determination. Barry noted, "We would survey farmers in the community and ask what you need? What are the new things coming out? Is there a disease out there that you're having a problem with?” Arthur added, "The county extension agent was a great resource to determine the needs because they are working and interacting with adults in the community on a day-to-day basis.”

During the discussion of motivation for adult learners in programs, participants felt strongly that the monetary value played a vital role in participation and overall success. Dennis stated,

The bottom line is easy; it [adult education classes] put money in their pocket. That's the bottom line for an adult. If you take an adult learner and do something in one, two or three classes, and put $\$ 400, \$ 500$, maybe $\$ 3000$ extra in their pocket, he’s going to be back, he knows you're there to help him.” He further added that "you could come in and not know a thing and leave, and have enough knowledge that you could be successful with whatever you want to do.” Charlie added “the biggest advantage of teaching adults isn’t necessarily the content, but how to save money. If I bring in a Veterinarian to speak, there won’t be an empty seat in the house, everyone, I mean everyone want's free veterinary information. Although adult education falls under the spectrum of both the agriculture instructor and county Extension agent, participants recognized that the agriculture instructor should use 
their resources for the betterment of the overall adult education program. Arthur stated, “Sometimes the Ag teachers want to be the know-it-all and don’t want anyone helping them conduct adult classes. Not me, I spread it out.” Agriculture instructors have a good base knowledge but sometimes lack specialized knowledge or training in an area that adult learners want. Participants noted that they used specialists and individuals from industry to help fill the knowledge and skills gap. Dennis stated, "The county forester came in, we actually went out in the woods and cruised timber, sawed the timber, graded the lumber, and they left with knowledge I couldn’t alone give them.” Barry also added, We would bring in people from the university [WVU] or get a specialist. We would teach some of it, the extension agent and the specialist would teach some of it and it was just a natural part of conducting adult education programs. While discussing the overall impact of implementing adult education programs, the participants vehemently stated that the programs were very important in gaining support from the community, which led to overall program success. Arthur stated, "Once those people [adult learners] propagated themselves within the community, the word about the ag program spread like wildfire.” Charlie stated that his participants,

Were highly influential society people and it's all about getting those people in your corner. If something comes up, and you need them, all it takes is a phone call to some of those young and adult farmers and those guys are right in your corner.

Theme 1d: Technology. When directing a total agricultural education program, the participants were adamant that technology was a very important factor both in and out of the classroom. The use and implementation of technology in the classroom setting has a positive effect on teaching and the student learning experience. Edward stated, 
Technology in the classroom is a must because our students seem to be more visually inclined today. It's so beautiful when you can be teaching judging per se, and you have the actual animals walking there on the screen for you instead of having still pictures or having to leave the classroom. That was so awesome. When asked about how technology transformed teaching Charlie commented, I can take my students down to the little old slaughter house in Milton or somewhere, but why do that when I can use technology and pull up a virtual field trip to Swift, and watch them process 10,000 hogs in a matter of 30 minutes or so. The students are in awe of the magnitude and you can bring the world to their classroom. And that is a remarkable thing.

As new technology emerged, the agriculture instructors had to keep up with changing times and adopt the new technology in both the classroom and laboratory settings. In reference to technology and facilities, Arthur stated,

I had to keep up on new greenhouse technology. The new type of control systems were coming in and we had to adapt. Our greenhouse was very automated with a shade system, fog systems, thermometers and all of that ran off of a computer timer.

Although the participants adapted to the technology, they held that they had difficulty learning and transitioning with the new technology. Dennis stated "It was hard for me to understand at first, but as time went, it made teaching easier for me. Edward added "I found it [technology] a tremendous challenge, because I am of the old school.” The rapid development of technology also created challenges for the participants during their careers. Dennis added that it changed his role as an instructor by commenting, 
"Before computers, we the teachers, were the information center, we provided bulletins, and information so on. As time progressed, we didn’t become a provider of information, we became the filter where we filter out all the junk and say, "this is important and this is true, and this isn't true.” And so on, we became the filter.

During the discussion of adaptive technology, the participants were adamant that cellular devices were a "double edged sword" with regard to teaching. Arthur stated,

It can be a nuisance but at the same time, they [cell phones] all have cameras on them so the student can take a picture of plant problem, and I can put it up on the Smart Board and we can all learn from it. It's transformed the student experience. Furthermore regarding cell phones, Charlie stated,

The students get excited about a project they completed for a class and they share it on social media from school and their friends and family see it. That creates a buzz and people outside of the classroom start talking about what is going on and are excited. So I see a lot more positives than negatives.

Theme 2: Support. The second theme derived from the interview data was support. Throughout the interviews, there was great discussion about the outside factors that affect directing a total agricultural education program. The agriculture teachers highlighted support in five areas: school administration, county administration, state administration, parents and community. 
Theme 2a: School administration support. When directing a total agricultural education program, support from school administration is paramount for overall success. Principals are first in the "chain of command" with regards to educational leadership structure. Administrative support from within the school can have major implications on curriculum, ability to operate an agriculture program and directing FFA, as well as developing support with educational leadership hierarchy. The teachers in this study were adamant that during their tenures (which greatly varied in length) as agriculture educators, they were very fortunate to always have supportive administration within their respective schools. Charlie stated,

I've gone through a lot of principals during my career. They may have changed every two or three years, but I’ve never had a principal that wasn't anything but supportive of the program. So I've been fortunate. Students played a huge part in the overall success of the program, but overall, administration was a big part of it too.

Arthur added, My school administrators were excellent because I grew up with them, some of their kids were in my class, I knew them. In my 33 years, I always received whatever I wanted from any of the administrators, never had any problem. In fact, I had more stuff than I probably needed; never wanted for anything. When starting a career in agriculture education, gaining support from the school administration early is key to successful career and program. During the first years of teaching service, agriculture teachers are required to "prove themselves" early which lays the foundation for a strong and prosperous career. Charlie stated, 
At first, there were a few things that we had to work out with the administration. When I first started teaching, I wanted a lot of things from my principal. We wanted to do this and that, but most importantly I wanted to take my students to national convention. My first principal wasn’t on board, but finally told me that if we won something that qualified us for nationals, he would let us go. So, that was our goal, I had to prove that I was worthy, and my students shared that. And, so we won something like 18 months after that request to him and that proved our worth and come time for the next convention, we were there. It was tough at first, but from there on, we had their support.

Having a strong school administration support for an agricultural education program can also aid in protecting resources and stature of the program. When discussing the impact that principals have on agriculture programs, the teachers noted that if something went awry, the school administrators always had their backs and fought to protect them. Edward stated, “They always had our backs. If we needed some influence when approaching the county administration, they were always there to go to bat for us. I couldn’t have asked for a better protector.” Charlie added, If someone had a problem with what I was doing or didn't like how things were being run or the decisions I was making, my principal had my back. My principal would always say, “Now, we’ve hired him. He’s the professional, let’s let him run the program.” My administrators were very influential and protected both the program and me. It is vital to have their support in order to survive in this career. 
Furthermore, when agriculture programs are strong, administrators become strong proponents of seeing them survive and benefit not only students, but the community as a whole. Dennis added,

When I first started at the school, the only program that basically amounted to anything was the agriculture and FFA program. At the time, sports were in shambles and those teams couldn’t win anything. On the other hand, our program was winning right and left and we was really the only successful thing around that amounted to anything. When you are the only game in the house, it's a lot easier to play. And we showcased that fact and as we grew and got stronger and better, everybody in the school and the community looked at us and wanted to be as successful as us. We were what they all aspired to be and that carries a lot of leverage with support from the administrators. They saw all the good that we were doing and made it a priority to see to it that we had what we needed and were our biggest fans.

Theme 2b: County administration support. County and local administrations play a vital role in agricultural education programs. County administrators provide guidance for programming, funding, and approval for many facets of the total agriculture program. Establishing relationships and support from the county administration is an essential component of not only being an agriculture teacher, but a director of the total agriculture program as well. Barry stated, “They knew what the program was and understood the importance of it. You have to be on a first name basis with the superintendent and board in your central office. It's vital if you want to be successful.” 
The teachers were adamant that the relationship with the central office must be made very early on in one's career. Edward added,

I found that the quicker I establish that relationship, the better the administration is going to accept you. I'll be honest; I don't know any administration that would actually fault you for being successful in your program. So I think the challenge that I had, I started a program right, I showed them that I want to make improvements, so I begged for a meat lab. And I think you have to do your part and prove that it's going to be feasible and it's going to be educational. That's the test.

Within the county administration sector, the teachers recognized that they were very fortunate to have support from the central office. This support allowed programs to become successful through funding, travel permission and facility upgrades. Edward stated, "I always had a supportive administration, but never was I disappointed in what they could do for the program.” He further added,

I never once was questioned on where I wanted to go. I never was questioned on how we were doing as a program, but they saw the outward success and that helped. They were always very cooperative letting students out of school or giving release time to travel for contests and events. I would actually say that support is important, because if I'm on the verge of maybe not wanting to be a good teacher, those things could bother me, they could really bother me, but I was fortunate to maintain the route. As long as I've got a decent support from my administration, or good support, we will continue to be successful and so, I've been fortunate probably in that factor. 
The teachers in this study indicated that ensuring a strong relationship could sometimes be a difficult task but promoting and exhibiting student success always reinforced the relationship and support from the county administration. Many tactics can be used to showcase student success to gain support. Arthur stated, "We always made sure to invite our county administration and board to events. It’s a must.” Barry added, Well, Ag programs are notorious by themselves, but we made sure to make our presence known early and often. We had a lot of activities going on and you just invited board members. You invited central office to those activities such as Ham, Bacon, and Egg Show, FFA banquets, awards presentations and student presentations. We were very successful in promoting our program and it paid dividends. We were very successful in competitions because of a great group of kids. We were in front of the board multiple times a year asking for some help with national travel, funding, and they were very supportive of that. They love to see the students taking part in the activities within the community.

County administration is responsible for determining the length of extra-duty contracts for agriculture teachers. The teachers were adamant that in order to be successful as an agriculture teacher, a 240-day contract was imperative. Barry noted, “Our summer employment was a way that we really connected with the central office. They saw what you were doing every day and that helped prove yourself as a teacher and justified your program.” Edward noted that one of the only issues with his county administration evolved around cutting back employment from 261 days to 240 . He stated,

The only issue I had was when they cut back our employment contracts. That was a big crunch on the program but we went to battle to keep those days. I do think 
that we need those extra days to get everything done that they expect us to. It will be a challenge for years to come. It's important to keep in touch and report to the county administration on what we are doing on those extra days. They sometimes lose track of what we actually do and once they see all the extra duties, it secures our justification for the extended contract. It's a fight and a person in that position needs to be prepared to go to battle because had we not fought as hard as we did, we would have lost again and been reduced to 220 days.

Although themes of strong support from the county administration was derived from the interview transcripts, the teachers noted that there were great barriers and inhibitors the county administration put on their programs. Receded support from the local level is found in the form of bureaucracy, lack of funding, and ignorance of agriculture programs. Barry stated, "I think they are a true barrier if you talk with people that are in the system. It wasn't a barrier for me 30 years ago, but it's a barrier now. It's mainly cutbacks; it's not necessarily their fault. Charlie added, "I was blessed at first, and then it changed over time. One of the hassles was never having enough money, and then, the bureaucratic red tape. It's the reason I retired when I did, just got tired of it [sic]. He added, When we wanted to build a meats lab, we really didn't get much help from the county. We had to work for it on our own. I was fortunate to have connections with a state senator, and before she left office, she got us $\$ 60,000$ earmarked from the state for an animal-processing lab. We got some program modernization money, and put some of our own money from the program and greenhouse as well as donated labor to finish the facility. 
Lack of knowledge and ignorance of the agriculture program was noted as another challenge posed by the county administration. Dennis stated,

Gaining the support of the local superintendent was an educational process too. A majority of them would come out of academia, or other programs like science or phys-ed, or whatever, they didn't realize the full value of the Ag and FFA programs, and again, it was an educational process. We had one superintendent here that was a little bit uppity. At the time, I had a student who was a junior who made $\$ 34,000$ one summer just selling tomatoes. And the superintendent was a little bit discouraging when he found out and made some kind of obscene remark about the FFA program. Well, the student and I trooped right in, knocked on his door, and he told him “Hey, I want you to know, I made \$34,000 this past summer just selling tomatoes. How much did you make?” After that, our problems with him and his administration were over.

Theme 2c: State administration support. Support from the state agricultural education administration is a lucrative part of operating a successful agricultural education program. The teachers in this study were strongly believed that during their time directing agriculture programs, the state supervisors were extremely valuable and were considered an asset to their programs. Edward stated,

As far as the state administration, they have always been so cooperative and supportive. I often wondered whether or not they really knew what was going on in the local level because I normally didn't see them except in a state meeting. But as time went on, I saw more visitation and that helped us when we needed to their 
stature in education to help us through a rough patch. The cooperation between our local level and the state administration has been very, very good.

Establishing connections and keeping open with state administration is also an essential aspect of operating a successful program. Barry commented,

The support that you got from the state department within agricultural education was essential. They knew who you were and you knew who they were and that was paramount. Keeping communication open with them is a key to being successful. You could go to the state supervisor with an idea or ask them advice and they would always support you and your needs or wants. It's a little different than just knowing them than being on what I call a first name basis. They know what your program is. If you've got a quality program, they'll support you, they'll get you what you need and it just flows right down the line.

State administration was viewed as an essential source of funding and support for implementing and funding programs. Dennis commented, "The connection with the state made a huge impact on the program. They provided us with some assistance, some money by grants and so on. It allowed us to get things we needed for the program to be successful. Edward added,

One of our first big moves was the fact that we got a small engines program up here at the high school. They helped us establish the small engines program as part of our Ag Mechanics program. If it weren't for them, I'll tell you what, that would have been a tremendous setback for me. We were able to get that and that was extremely important to our program. 
Theme 2d: Parental support. When directing a total agricultural education program, parental support is a key component to overall success. Parents play a vital role in assisting students and helping them achieve their goals as well as promoting the agriculture program in the community. Some parents of students in the agriculture program were once former students from an agriculture program and FFA members. Dennis stated, “Their parents provide a base. Where do our students get that strong base? The FFA. The parents were always former FFA members and knew the expectations and what was asked of them. That concept gets passed on.”

Gaining strong parental support is a key process for an agriculture teacher to build support for the overall program. It is crucial for agriculture teachers to gain respect and support from parents very early in order to have a positive experience directing the total program. Edward stated, “Parental support, I really can’t think hardly of any negative experiences. I think I sold the program right and did so very early. We started from the bottom and we worked our way up, it then became very successful. Arthur added, "Parents like to see their kids' names and pictures in the newspaper, and when you show that you support them, they [the parents] are in your back pocket.” Parental support for agriculture programs can easily be gained through outward personal growth and promotion of student success. Edward commented,

Student success in the program boosted tremendously when we added the greenhouses to the program. It just simply ignited the students and the overall support from their parents. When we started having success with their kids, we have to remember, it wouldn't be there if it weren't for their kids and we wouldn't be in business. And so, when their kids started having great success, operating the 
program was easy. Seeing that interaction, experiencing that support from the parents, and sharing the moments when they see their kids have success, I think that's what inspired me.

Strong parental support has an effect on multiple facets of directing the total agriculture program including involvement with FFA, classroom discipline and teacher standards. Barry noted,

Our FFA program was very strong because of the parent support. Whether it be a fundraiser, chapter function, career development events, competitions, traveling locally or across the country, our parents were there to support the FFA. All of those things get the parents involved and help the strength of the program. Among the various clubs and organizations in the school, FFA always had the best parent support because they believed in the value of what you were doing and bought into the investment of how important it was to the success of their kids.

When discussing the relationship between parental support and classroom discipline, the teachers were adamant that having a strong parental support base was very effective in reducing and eliminating discipline within the program. Arthur stated, Discipline as a whole was easy. I had many of their parents in class and having that knowledge and relationship was an easy way to combat discipline. They knew that mom and dad were only a phone call away, so that problem worked itself out.

Barry added,

Support from the parents was tremendous and that was great when it came to discipline. It was just kind of a given thing. You got to know the parents and 
when you got to know those parents, your discipline in your classroom was almost non-existent. They knew that mom and dad knew you and supported what you wanted them to do and things like that so you know, it's our parent involvement, parent support that makes agricultural education so special and unique. Other programs and teachers in the school wish they had this crucial and important relationship.

Parental involvement and support can also have an effect on agriculture teacher standards and performance of directing the total agriculture program. Dennis stated,

Parents and their support of the program was great, but had an effect on me as a teacher. The strong support, it was challenge to not only me but also the other two teachers in the program. We had to be on our game and ready to go every day in class. We had to do so in order to stay ahead and be competitive with the program. Many of the parents had been coming the adult classes in the evenings and knew everything that was going on. They were checking up on the students and what you were doing. Unlike the other programs in the school, they knew what we were doing every day and when things were supposed to happen. That kept us on our toes, but made us better teachers and advisors. Having that close connection not only helped me, but the students as well. When the support was there, the level of education rose for the kids and you can't trade that for anything.

Theme 2e: Community support. Throughout the formal interviews, it was noted that the agriculture teachers attributed overall program success by having a strong community support for their programs. More specifically, it was noted that important outside factors included a strong working relationship with the county Extension agent, 
strong advisory committee, and overall community involvement. Each factor was important to not only the health of their programs, but the overall value and benefit that students received. Charlie added, "We had a great working relationship with the extension office and that helps you and your program.” Dennis stated, I couldn't have had any better of an experience as it relates to working and having the support from the county extension agent. It was just a good, solid relationship. He was a great communicator, and he realized that in order for him to be successful in extension, he had to surround himself with the people that were successful in agriculture. We as agriculture teachers shared that same philosophy. That relationship and philosophy helped us both when we went to put on adult education programs. We pooled our resources and it helped us grow as a program and as educators. Both of us had a common goal and we found ourselves working with the same people and students all the time and that was very important for both of our programs. At one time we wanted to change the county fair so that it was a learning experience for the kids. Our goal was to maintain that it was a learning experience and our combined support and efforts made sure that it continued to be that way.

The teachers stated that having support and a viable relationship from the county Extension agent also helped them with respect to directing adult education programs within the community. Charlie noted, "I wouldn't change a thing. The more involvement the better, as long as you're working together with a common goal for the community. As long as you don’t take over their territory, they won’t try to take over yours.” Barry added, 
When we had adult evening classes, the extension agent was involved in all of those. In fact, he got most of the speakers for us. We got the adult farmers in and he got the speakers, so it was just a really good working relationship. I don’t know that you'd succeed or survive, I should say, if you didn’t have that support and relationship.

Advisory committees. Support from the community in the form of an advisory committee is imperative to having success within an agricultural education program. Barry stated, “I don’t think we rely on them enough now. Their role is to advise, not dominate you. They can be one of your best assets as a teacher.” Since the advisory committee is made up of members of the community, the program is shaped and directed from the needs and support from within. Dennis stated, I think everyone should an advisory committee, but whether they function or not is a whole other ball game. The committee kind of points you in the direction maybe you ought to go with it, or teach; especially if you're not teaching something that you should be teaching in the community. They can help with your needs, express needs rather than be the teacher. That's their role. If you have a strong adult education program, they will encourage that committee to help you fit their needs. If you're real lucky to have a board of education member on your committee, you're set for life. Again, you have to have a good, sound program that's showing benefit. Even myself, I wouldn't encourage anybody to give anybody support that doesn't do anything to benefit the kids or the community. With regards to the composition of the advisory committee, a broad group of influential agricultural supporters should be sought when selecting the committee. Charlie stated, 
"You want to find people who are interested in agriculture, and people who want to be successful, and people who have a knowledge in agriculture.” Dennis added,

You want to get a broad base, such as parents, business people and bankers, agriculture community leaders, farmers, and maybe even Farm Credit. That group is your best bet to provide you guidance. When I started teaching agriculture, I had a person on the advisory committee that was owned a hardware store. I tried to encourage him to buy hams and bacons at the shows and he never did for a while. I had a student who made $\$ 1240.00$ by selling feeder pigs to other people to raise for ham and bacon hogs. Once he had that check in hand, I told him to go to that hardware store, ask for the owner and make sure he sees that check and ask him to cash it for you. So, he did and the next year he was at the ham and bacon show buying hams and bacons. He realized the value of it and when he came to the next advisory committee, he became the mover and shaker of the group and wanted to make sure certain things happened. That was key to gaining their support and helped the program tremendously.

Overall support and involvement from the community is a vital aspect of a successful agricultural education program. The community is comprised of many resources that are of great benefit to an agriculture program and overall student success. Community support can be difficult to obtain for new teachers and newly formed programs. Charlie stated, “At first, it was rough because of no community support. It takes time and support has to be built. It's a gradual process, but you have to find the influentials in the community and make sure they know you.” Dennis added, "When you start out teaching, you must have a goal. But if you're progressing and you can show that you can make 
things in the program a little bit better, or maybe educate more people, then success bleeds success." Edward noted that to quickly gain the support of the community agriculture teacher must "sell the program to the community through the use of exposure. You must get the kids involved and showcase them to the community. They see young people doing well, and they will always support that.”

Procuring and maintaining a strong community support base was noted as a task that can easily be accomplished through a strong curriculum as well as directing an FFA chapter within the program. Edward stated, Support from the community was gained not by me, but through the success of the students. I taught seven or eight years before I really got the program off the ground and that was tough especially when I needed support from the community. I have to be honest, adding the meats program to the curriculum was an extremely important move for this community. And with my background and training in school with meats, it was a perfect setup for the area. When I added that program, it really inspired the community. They saw something new that was happening, something that was being done to improve the education of our students. That was instrumental for the success I found in my career.

With regards to gaining support through the FFA he added,

The first thing you have to do as a teacher is prove yourself and then you don't have any problems gaining or keeping support. You have to prove yourself that you can control or discipline, and prove that you're really interested in the kids. As a teacher, you have to prove that you are planning on making progress in a particular program or whatever it is and you're going to put those students on 
display. We can't secretly keep our kids without showing the public as to what they can do in our program. We have a beautiful place to do that through the FFA. That's it.

Supervised agricultural experience. Having a strong community support system also heightens the overall student experience through supervised agricultural experiences and learning facilities. Dennis commented, When I started, we didn't have a greenhouse, but knew that we needed one. We sold plants and one day I had a lady who asked a ton of questions about why we didn't' have a greenhouse facility. Next year, we had a greenhouse. I didn’t realize I was talking to somebody that was going to push some buttons and see that we had proper facilities for the students.

Having a strong reputation within the community greatly benefits business relationships for students who need financial support. Dennis stated, I had many students who needed capital funding for his SAE. Having the relationship with the local Farm Credit helped them pursue their goals within the SAEs. They would loan students a limited amount of money on their own signature, as long as they had a business plan and showed how they were going to pay it back. That helped the program tremendously.

Strong community support also plays a vital role for students who have a placement SAE. Barry stated,

One of the best aspects of having a supportive community was the assistance and ability to place students for their supervised programs. Most of my students were on the placement end of the spectrum, which made it challenging. I'd go out and 
work with employers within the community and talk to them about students who had special interest or specialization in the area of business they were involved in. I sold the value of the experience quickly and in return, established great working relationships for the students to carry out their SAE. By doing that, you knew what employers you had, and they knew they could count on you to help them with employees. It was just a natural part of the program. They looked at the Ag program as a help to them, and we looked to them as a great asset to our program. Dennis added, We gained support from the community to help our students with their SAEs. And everything we did over time was to beat that banner and showcase that students were learning. And as a result, when we started the county livestock sale, it was only $\$ 42,000$ and last year, it was over $\$ 500,000$. Now why did that happen? The community saw that the fair was a learning experience for close to 300 students and the community still knows that today it is still a learning experience. And through that support, we have maintained a fair that was educational and entirely youth oriented.

Theme 3: Directing FFA. The third theme that emerged from the interviews was perceptions of directing the FFA. Although FFA is only a small component of the total agriculture program, it is often the most visible and recognizable aspect of agricultural education. Edward stated, “It became a major part of our program. It's the showcase of what we teach. Agriculture teachers wear many hats and one of those are advising the FFA Chapter. Arthur noted, “The FFA is an important component because this allowed the student in the classroom to be a leader in the community. It showcased what we did as 
a program while providing many opportunities that don’t happen in the classroom. Dennis added, “The FFA taught the students that they aren’t representing themselves anymore, but instead you are representing your chapter, school, community and state.” Edward stated,

Well, I think the first important part of directing the FFA was that we try to teach the qualities of leadership because I think the chapter goes in the direction that their officers go. And I try to make sure that we provided a great foundation of leadership training so that my officers would be true leaders of the chapter, not the advisor.

It was noted that even though the agriculture teachers, as advisors, were responsible for directing the organization, student leaders were responsible for the overall work of the organization. Barry noted, “I didn’t run the chapter, the officers did. That is important to keep in mind because it is truly a student organization." Edward noted, "The building of chapter leadership and bring it to the top through your officers was the start.” When discussing officer responsibilities, Edward noted, "I like to refer to my president as the captain of the ship. If you don't have the right captain of the ship, then we're not going to go very far. Form a foundation of great leadership training." Dennis stated, Each officer would take on certain responsibilities. The president of course, would lead, the vice-president would make sure that there were committees and that they were doing their jobs. The secretary kept good minutes, that's key. The reporter was our publicist and made sure our name got out into the papers and the treasurer kept the books. It was done the way it should have been and everybody grew by it. It worked in a way that was successful and that spread like wildfire. 
When chapter elections came around, we would have 5 or 6 running for each office, which was a good thing.

Election of officers was noted by the teachers as a very concise process that was left up to the body of the organization. Dennis stated, "It was always democratic.” Charlie added, "It was on the students, it was their organization. You advised them, but ultimately it was up them.” The teachers expressed that the use of a nomination committee was a positive tool when electing leadership within the chapter. Dennis stated, Anyone could run for an office, but it was done by a nominating committee. All the potential candidates would go before the nominating committee, they couldn’t get nominated from the floor. As advisors we would set in only one committee, so we wouldn’t dominate. We would just listen and let the kids make the decisions. Most of the time, they did what you expected out of them. If you expect great things, they'll come true.

Once officers were elected, the teachers expressed that the use of an officer's retreat was a good tool to start building the team leadership early. Barry noted, "I think that is a very effective tool.” Dennis added,

We always had an officer's retreat, which I think was great. In the summer, we would go two to four days, and just go with the officers, and do nothing but leadership things. We would do activities that would cause them to work together as a group. We tried to work it out to where we would go canoeing. By doing that, there might be a few officers that couldn't get along very good with each other, so we'd put them together in the same canoe. Very quickly, they learned that they had to work together, or they wouldn’t have much success. 
Theme 3a: Importance of supervised agricultural experiences. Throughout the study, it became very evident that the teachers placed a very high importance on the student supervised agricultural experience portion of their curriculum and FFA. The participants recognized that the SAE had a profound impact beyond classroom instruction on not only the students, but their communities as well. They also stated that a valuable SAE not only teaches skills, but enhances program success. When asked about the importance of SAEs, Edward stated,

Well, SAEs, we can’t forget about them. They must be a part of our protocol. It helps the students put into practice what they learned in the classroom. I tried to make sure that every student in the program had an SAE. I would average about 93-94\% of my students who would successfully complete their SAE for the year and I felt so good about that [sic]. You'd like to have $100 \%$, but sometimes we fall through the cracks. I just feel so good about teaching the skills of record keeping, it’s a skill that we need throughout our lives [sic]. SAEs are extremely valuable and I hope that we'll continue to have those as an extension of what we learn in the classroom.

When asked about supervising SAEs, the teachers admitted that a real challenge of supervising students is finding an experience that works for them. Arthur stated, "It's hard find something for everybody, but somehow we as Ag teachers, made it work." Barry added, "We tried to find them something that was adaptive to their skills, yet at the same time earned them money and valuable experience.” Teachers noted that SAEs were often production or placement, but many found great success in using school programs and facilities to launch SAEs. Edward noted, "The greenhouse, this where the greenhouse 
comes in with respect to SAEs. Students that had no facility at home, this is where they worked as well as the co-op garden which was about the major type of land we could deal with.” Charlie added, “Our meats lab was turned into a deer processing facility during the season and we normally paid out about $\$ 1,800.00$ to students for working in the meats lab. Now, to me that's a very valuable part of SAEs.” When discussing placement style SAEs, Dennis stated,

“That was another thing that was kind of unique to this area, and I really enjoyed it. We encouraged kids to work and we had about 30 co-op stations within the community. Many of those businesses had leaders that were once FFA members and that made for a great connection for students. At one point, everybody who worked at Kroger's and McDonalds at one time was a former FFA member and you can’t beat that network. We also encouraged kids to get into their own businesses, and those kids that got into their own businesses were more than accommodating to hire somebody that would work through our FFA program. Success bleeds success.”

When implementing a production SAE, the teachers were adamant that even though it may be hard for everyone to produce something, the overall "take-home” value to the student was very important. Dennis stated,

"We agreed when I came to the program that everybody could take an animal to the fair, but if they took an animal to the fair, they had to have something else. And we always encouraged that something else had to be something that would put money in their pocket whether it be raising hay, or raising green beans, or sweet corn or tomatoes. Times were much different back then. The money that 
kids had was the money they worked and got, they couldn't stick their hand out to mom and dad and say, "well I need this.” They had to earn it. And when you have a kid that basically doesn’t have a pot to piss in, he makes $\$ 2000$ or $\$ 3000$ raising green beans, you don't have to encourage very much. They want to do it to put money in their pocket.”

Furthermore, the teachers agreed that it wasn't all about them earning money, it was about them taking pride and showing off that pride to others. Edward commented, "A great outlet was the state fair, showing of market and purebred hogs at the state fair. It was something nice for the students to look forward to and a great, competitive and educational place to show. We eventually had a county fair that came in there, and that was another outlet for them to show their animals off to each other, but the community. They took great pride in themselves and their animals by showing off their hard work so that others could see and it was so great to see that.”

SAE supervision. During the interviews, the teachers were in agreement that supervision of each SAE is not only an important job for the agriculture teacher, but a vital part of the experience. Supervision of SAEs can be conducted both informal and formal. Barry stated, I visited a lot of my students at their job sites. So, you get to know the employers in the community, naturally, which is important. But you also get to visit the student, on the job site with their interests. That's what they're interested in or they wouldn't have taken a summer job there. You also get to meet with their 
parents and I think that's a connection that Ag people get that regular high school teachers don't get nor ever understand. It makes us Ag teachers a unique breed. Arthur stated, "Sometimes I made a formal visit, while other times, I may have seen them out working and observed their work and interaction with others and that's where it becomes real.” Barry commented, "We made a conscious effort to visit everyone at least once, if not more during the year.” Dennis added,

Supervisor visits are so important to a successful program. That's the reason why we could have a great FFA program. That led to the reason why we had lots of State Farmers, and many American Farmers. We had that success because we as the supervisors, knew exactly what the situation was for every one of our students.

Supervisor visits were a tool used by the teachers to not only visit the students, but check their records for accuracy and completion. Edward stated, "A major part of my visit was the record book. Now they are all digital, which is great. Although I'm old school, I admire the state to using the new digital system. I guess it brings us up-to-date.”

Theme 3b: CDE team selection. When selecting team members to compete in career development events, the participants in this study stated that they used several methods to make the final determination of team composition. The teachers discussed the various methods and the implications of using those methods when compiling team members for competition. Regardless of the variations in team selection, the teachers agreed that it all started with student performance in the classroom. Edward stated, I think it starts in the classroom. It starts with the teaching of leadership skills, and the teaching of knowledge of meats, teaching plants, selecting animals for show, 
and for show animals over hams and bacons. I try to teach those things in the classroom so that I can find those students that can rise to the top in their knowledge of what you're teaching. Those individuals basically became the members of that team or became my speaker. Those individuals basically proved to me that they are willing to learn and excel in learning and putting what is learned to use. There was a concise method, and I didn’t just put up a paper and ask you to sign up if you wanted to be on a team.

Charlie also insisted that the genesis took place in the classroom by stating, I always agreed that a sound classroom program would allow you to be successful in a contest. We didn't teach contests, but you could take the skills that they developed in the classroom, adjust it just a little bit for the contest, and they would be successful, if they would work at it. And it's because of that philosophy that I'd say we had great success.

CDE team selection was also carried out by characterizing student strengths and weakness through observation in the classroom setting. Arthur stated, I had some of the kids who could learn the weeds in class, but when it came down to it, they couldn't remember all the different grasses and weeds for the agronomy contest. I had a kid who couldn't do math, not that he couldn't do the math, he just outright hated it. On the flipside, that same kid was highly proficient in remembering all the plants. He did better than some of my best students in the contest, so I capitalized on that. And once they realized that I was capitalizing on their strengths, and not their weaknesses, they studied even harder and harder. 
Non-traditional selection methods for selecting teams based upon academic performance outside of the agriculture classroom was also used. Arthur stated,

I went to the guidance counselor because I didn’t know everybody, or didn’t have all the kids in class. I found out who had the best math score, the best reading score and I recruited them. If you can read and do math well, you're probably going to be able do well in a contest. In addition, I also found that recruiting them on the bus on the ride home was also a very effective method as well.

When discussing selecting career development team members, the teachers were adamant that student motivation and determination provided great weight into their decisions. Students become very competitive when there are multiple individuals vying for a seat on a CDE team. Arthur commented, "It got to the point where they would start competitively fighting to get on the team.” Charlie added,

When I started it was like pulling teeth to get on the team, but once they got the taste of winning and success, it was on. One year I had 14 students to try out for the parliamentary procedure team and I could only keep seven. I had to divide them into two teams and have them practice against each other, and that was too many. That's just as bad as not having enough, but they fought for it. I eventually had to start cutting people, which was a new concept to a group who were initially hesitant to step up and participate. I didn’t play favorites to officers either, because they had to really study because some freshman beat them out of the seat. Arthur stated, “They started weeding themselves out and we started an in-house competition. We held one every night and I found out the most about their ability from those simulated competitions.” Dennis commented, “Just because they might be a super 
genius, and not study, somebody who'd studied hard beat them out. Selecting teams had a way of working themselves out, which made my job easier.” Edward added,

We would often have chapter competition. Once those individuals rose to the top and showed they were interested and showed that they could handle it, they became the members of my team. We would put those people on display to make it real. We developed a speaking program with the grade school and, in fact, we sponsored a speaking contest for them, public speaking, extemporaneous speaking, and so, this helped to inspire those younger kids. And sometimes it becomes surprises. Some students may back off from it the first couple of years and then all at once they'd catch fire and they want to become a member of the team or want to be the speaker.

Theme 3c: CDE team training. When training career development event teams, the teachers were adamant about when training should occur. Some teachers found that solely training after school was the most effective method, whereas others found that training teams from a "co-curricular" approach was acceptable as well. Arthur stated, "I did all the training after school. Everything was afterschool because I didn't always have all of my teams in my class. It was too difficult.” Charlie added,

I never trained during the day outside of trying to show them what parliamentary procedure was. Sure, in freshman classes you say the creed, and you work on that. You're constantly pumping that contest up and they get excited about it. But all those contests that we worked on, those practices were all outside the school day, which makes for some long days sometimes. 
In addition to timing of training, Barry stated, "I liked to train outside of class, but especially during mechanics, you may be teaching that concept or portion of the contest, so they get to practice while learning it in class. So it's a win-win scenario for time.”

It was noted that training CDE teams is an extension of the classroom learning. The classroom instruction is the foundation from which teams specialize in certain areas and expand upon that knowledge. Charlie noted, "They get their base in the classroom, and we take that and curtail and tweak it to fit the contest. Its classroom knowledge turned practical and that is what makes it unique.” Arthur shared a technique that he used to train teams,

I attacked it a little differently. Their job was to study. They may not be able to be the best in the contest, but they had to know what to do to make the attempt. The practical part of training for the contests was the easy part. I liked to focus on the test and literally beat them to death, the test that is. From the test, I could really find out where the weaknesses were at and what we needed to practice more on. I never dwelled on the weakness, I used them to springboard their strengths. I also approached practices initially as individual based, then it became a team practice. Another important part of learning and training was knowing terms. If the team had some downtime, I told them to go the glossary in the back of the textbook and read terms. That speeds the learning up and by reading the terms, and having a larger knowledge base and vocabulary. There is a good chance that another team might not have heard a term before, but if you read the glossary, you're one step ahead. 


\section{Barry stated,}

The competition, its taking what they learn in the class and putting it to use. The competition were directly based on what you were teaching. It wasn't that you were just teaching for a contest, particularly in mechanics, you just didn’t do that. You taught your curriculum and the curriculum helped those students in the contest. We didn't per se train or teach a contest, we taught the curriculum and the university aligned the competitions with it well. And so, it just showed the student that they could perform under pressure in the real world.

When initially discussing training teams as whole, the teachers shared their philosophies on training teams and why they found them to be successful in their programs. Training career development teams was found by the teachers to be educational in nature, but with a highly competitive mentality to learn, retain and perform in the contests. Edward shared,

I always had the philosophy, and I still live by this very idea. You do not practice to lose, and that may sound sort of harsh, but we didn’t practice to lose. Now, we understand, there will be people out there that will be better many times. But, the further you go, the tougher it gets, but we don't practice or train to lose. But if we get beat, it's not the end of the world, if we have trained right, and we have dedicated ourselves right to the task.

That means, I'm always at practice, on time, and I enjoy what I'm doing. And if we get beat, there's just someone better than us. And you do it with high sportsmanship, not at the expense of anyone else. And that's my philosophy and I 
will, as long as I'm healthy, I will have that attitude because that's how my parents raised me, to be successful and that's what I want for my students.

He further stated,

If they have the same thoughts that I do on being successful, then when they fail, it's not their fault. Someone’s just better than you. There's always someone better. It's who can perform in the critical situation. I always said and still say, "Don't leave your best performance in the classroom, keep your best performance for the day of battle, or the night of the battle.”

Theme 3d: Success through FFA and CDEs. Throughout the discussion regarding the FFA and career development events, it became evident that underlying success and life-value of participation was a deep and emotional topic among the teachers. The FFA transforms students into leaders the leaders of tomorrow. Charlie stated, “I think all kids like some success, and sometimes it doesn’t have to be in something that they don’t think about. The FFA provides that success.” Arthur added, "The FFA made leaders, and by teaching them the value of that, they would do anything for you and I would do anything for them.”

It was noted that showcasing student success was a vital part of directing a FFA chapter. Students who are recognized for their accomplishments, hard work and success appreciate their organization and are inspired to continue the work of the FFA organization. Edward noted, "Being successful and being recognized for doing so is contagious. It really inspires them and I think I was able to continue it for many years throughout my career.” Charlie added, 
We made it policy that if our students won a state contest, they got a Carhartt jacket with the contest and "state champion" embroidered on the back. They took so much pride in those jackets that they would wear them till you think they were going to fall apart. Our head football coach right now was the first student I ever took to the Big E for tractor driving and won. His players have their nice varsity jackets and some of them say, “I don’t know why I would want that, I’ve got this varsity jacket.” My students fired back real quickly, “Yeah, but yours doesn’t say state champion.” Well, by golly, that was true.

Showcasing student success through banquets was noted as another great tool to recognize students for their accomplishments. Banquets bring together teachers, administrators, students and their families. Edward noted,

We always had a FFA banquet near the end of the school year and it was certainly the showcase. It was the showcase for the year and was remarkable. We really got great parent involvement and we invited students from down in the grade school so they could look forward to this someday. I always told my officers, no matter what we did during the whole year, this was an ultimate, and they put on the banquet. And you prepare them to be the showcase, to be the best .That's when you're the best. We were always successful with that.

When discussing the overall takeaway that students got from success in the FFA, it was noted that confidence was a key product of being in the organization. Barry noted, "I think it’s just the confidence and going in for a job interview or speaking, they've already been there. They've had the pressure put on their shoulders, they've performed, and they know they can do it.” Dennis added, 
Confidence for sure. They learned to believe in themselves, and they learned teamwork. My program developed the philosophy that what affects one, affects all. And if your fellow member or teammate wasn't measuring up to the standards, then you have to get back there and work with them, and pull them along with you. If you aren't working as a group or a team, you fail. They knew it was all across the board, everybody was equal. Again, success bleeds success. Edward stated, Let's take for example a parliamentary procedure contest. It's more than that. If we can train students to be able to present themselves to the public successfully and in a manner that is fully approvable, we've taught them a lifelong skill. And many of the failures in life comes when an individual cannot relate successfully to those around them, and I think that's what is important to us.

Theme 4: Supervising Student Teachers. The fourth theme extracted from the interview data was supervision of student teachers. Within agriculture education, teachers are often called upon to serve as site supervisors for student teachers. Site supervisors are generally responsible for the student teacher for 12 weeks during either the fall or spring semesters. They host the student teacher in their program as a mentor and provide guidance as well as performance feedback. Edward stated, "We were all student teachers at one time, so I tried to make it a wonderful experience for them.” Barry noted that supervising student teachers helped him as a teacher,

We learned from them also. They would come in with a little different flavor, a little different way of doing things. The kids, they enjoy that, the change. You learned as much from them as they learned from you. And that was a neat thing 
too because a lot of times, they kept you current because they were fresh right out of classes. They showed you knew things about teaching methods or lesson planning.

The teachers noted that they felt that the twelve weeks of student teaching training was appropriate to get a wholesome experience while at the same time, determine if they want to further pursue the profession of teaching. Edward noted, "I do think the twelve weeks are enough for classroom teaching, but there are so many experiences that happen after they leave. They don’t get to experience that.” Arthur added, “Sometimes I wish it would be a longer experience such as a full semester, but overall it works.”

The teachers felt strongly that the 12-week experience allowed the student teachers to determine whether or not they want to pursue teaching. Edward added, I think by the end of your student teaching semester, you know whether or not if this is for you. You either like students or don't. You like to see the acquisition of knowledge and understandings and see it beam in the face of kids or you don't.

Theme 4a: Feedback and performance. The teachers believed that performance and feedback are critical aspects of supervising student teachers. The supervising teacher is the first line of contact for the student teacher. They supervise and critique the student teacher on their performance in the classroom, laboratory and outside activities. The site supervisor also takes on the role as mentor and confidant. In addition, student teachers are responsible for going on SAE visits. Arthur noted, "I think the best part of the experience is the ability to give them feedback. They need to know how they are doing and it's important that we do that.” Edward added, "The supervisor is a seasoned teacher. They 
are the student teacher's best assets. If there was a problem, we worked it out, and learned from it.

When discussing timing of feedback, the teachers agreed that it was most effective to discuss performance at the end of the day. This method allows the teacher to reflect upon their day and talk about the successes and failures. Barry noted, "I wanted them to be successful. At the same time, I wanted them to get into a situation, where they had to work themselves out of. It wasn't cruel, it was realistic. When you're alone, there is no lifesaver.” Dennis added,

I tried to never let it go so far that they would bury themselves and not get out. But at the same token, I wanted them to struggle some. I wanted them to ask, that was the important part, because then they were getting serious about the whole business, it wasn't just routine. I never gave them the solution; I’d give them alternatives. They had to make the choice as to how to resolve a problem. They developed the ability to see, if you did this, then this is going to occur, then you have to be ready for the next one. Then they developed that ability to see far enough ahead. You're ahead of the game, instead of behind the game.

Edward expressed his view on feedback, I think it’s important to give feedback at the end of the day, just about every day, certainly every couple days. We would sit down after the kids had left school and we would talk. We would open the door, "Was there anything bad today that happened to you? Anything that dampened your spirit about teaching? Any problems you had that I didn’t see?” Sometimes I wouldn't be in the room with them, so I'd allow them to share everything. I stressed keeping open 
communication with them. I didn't want them going home and say, "This has been a terrible day and I don't have anyone to help me out.” We don't learn when we do that; we have to talk it out. None of us are perfect.

Theme 4b: New teachers. When discussing supervising student teachers, the teachers agreed that pre-service student teachers as a whole, were prepared to enter the profession of teaching following college. Barry noted, "I think they are prepared to enter the field. Sometimes we think they should know more, but we lose sight of the fact that we were once novice, green teachers too.” Edward stated,

Overall, I have feel that most of my student teachers have been very well prepared with the knowledge they need to start within the classroom. That doesn't mean they know everything. They have enough knowledge, and I think their educational courses have prepared them pretty well. Occasionally you will have some that aren't quite there. Part of that may be because of the type of program they came through, or their lack of overall knowledge of agriculture, which is a tremendous disadvantage.

When discussing weaknesses of pre-service teachers, it was noted that student teachers don't have a concept of how much time is involved with the profession. Teaching agriculture requires more than the traditional workday and often requires dedication after hours and on weekends. Dennis stated, “I'm not for sure if they realize what they are getting themselves into. It’s a very a demanding profession.” Edward added,

Overall, I question whether or not, the new teacher coming out realizes the time that's involved in running a good, solid, successful program. Our job is to put 
students on display and make sure they are successful. They just don’t understand the time involved that it takes. It's a total shock.

The teachers were adamant that the student teaching semester was a vital part of transitioning into the career. They expressed that it is vital to keep that experience as realistic as possible to ensure maximum learning and practice. Dennis stated,

They need to realize that although it's a time to learn and get practice, you can't lose track of why you are there. Student teachers have to realize that they aren't just teaching soils, or animals, but that they are teaching students. You have to turn them loose, and let them learn on their own. That is what happens in the real classroom.

Edward added,

We as teacher trainers out here, we need to give them as close of an understanding of what the real thing is about. I have had student teachers that are not very good workers after their regular school day. Then I've had those that stick with you to whenever they need to leave. Those are the individuals who are successful today. Student teacher training has to be as realistic as we can possibly make it. If there's hours after school when they should be involved, they need to be involved. They must understand that.

Theme 5: Perceptions of Directing the Total Program. The final theme derived from the data was the overall perceptions of directing the total program. This theme summarized many experiences and highlights that were elicited from looking back into the career. The theme included multiple factor that affected overall success such as 
background of teachers, challenges and barriers, balancing life, continuing education, career highlights and satisfaction, and retirement.

Theme 5a: Background of teachers. Within the agricultural education profession, the agriculture teachers in this study attributed their overall career success to having a strong agriculture background before becoming a teacher. The teachers recognized that their agriculture backgrounds played a vital role in their decisions to pursue a career as an agricultural educator. Charlie stated,

My background and love for agriculture had a lot to do with my pursuit of becoming an Ag teacher. One of the main reasons why I started in Ag and stayed in Ag was because there was something new coming up each and every day, be it a student's question about a plant, or this animal, or that animal is sick and all the different activities that we had going on. The total Ag program was the highlight of thing I thought.

Edward added,

I wouldn't have chosen another career. I say this honestly because I had a strong farm background thanks to my dad and mom. We lived in a great agricultural area and I learned to love agriculture and being outside. My experience in FFA and Vo-Ag was extremely positive and moved me to what to teach agriculture. I was successful and had a good training in high school, so my love was there. My background helped provide success for the future. With all of that experience, I was motivated to become the best Ag teacher I possible could be, because it was my goal to teach a certain number of years, ands retire from it. 
Furthermore, some of the teachers noted that they were fortunate to have received a great agricultural start when they were in high school, and then return to teach in the same programs that they grew up in. Arthur stated,

My coworkers were my teachers in high school. My ninth grade teacher was also my colleague when I became a first-year teacher. So I knew, I'd already been there; I was president of the chapter and that sort of thing. So, I really knew all the ins and outs of what was expected with the program. Made my life as a young teacher easier.

Barry shared a similar background and stated, "My background and knowledge laid out the groundwork for my success in the career. I grew up in this program, taught in this program, and became an administrator of the program. It's funny how things work out.”

Theme 5b: Challenges and barriers of teaching. After initially discussing their experiences as agriculture educators, the teachers noted that during their careers, they faced challenges and barriers. These barriers ranged from burnout to difficulty with working in a multi-teacher department. Many of the challenges faced were within the first five years of service, but it was noted that challenges and barriers persisted throughout the entirety of the career. Barry stated, “Those first five years are difficult. You're learning the curriculum, and trying to update things at the same time. You have to keep things going and it can get overwhelming.” When entering a program as a new agriculture teacher, there is a learning curve during the first years of service. New teachers have to adjust to being in a new profession, adapt to the program and community needs, live up to "standards" of the former teacher or program, as well as developing and “minting” a program to conform with their identity or area of expertise. Barry stated, 
Those first years were a huge progression for me personally and professionally. You start your career and boy; you're learning the curriculum as you go. When I graduated, a lot of the curriculum in agriculture mechanics wasn't taught at the college level and some of it shouldn't have been. I found out real quick that what I was teaching and what was being taught across the state wasn't uniform. I came into a top-flight agriculture mechanics program and I learned very quickly that I had to get ready in a very short amount of time. I had to get motivated, and I had to go the extra mile and train myself. I had big shoes to fill and my reputation, as a newly minted teacher was contingent on how well I could keep up with the program and keep the high standards that were set before I came through the door. One of the challenges faced by newly hired single teacher agriculture departments is the demand to teach high volumes of students of varying ability with very little resources or assistance. With respect to working in a laboratory setting as a single teacher, it was noted that supervision of students was very difficult and taxing. Charlie stated, It was tough being a single teacher. I kept asking for another teacher because they were stretching me thin. Still to this day, that county has never honored that request and hired a second teacher. Since they wouldn't honor that request, I asked for smaller classes for the benefit of the students and liability. That too hasn’t happened yet either and that was 35 years ago. When we had our freshman mechanics shop rotation, I would have 30 students in the shop and that ranged from 4.0 GPA students down to special needs. That was a challenge for me. Out of the 30 students, I had like six groups and divided some of them into the woodworking, cold metal, soldering, ARC welding and tool conditioning areas. I 
tried to go around and see each one of them and found that to be a daunting task. Think of the liability and the nightmares that could have happened. They definitely didn't train you to handle those situations in college!

It was noted by the teachers that the school calendar situation posed challenges and barriers to operating a successful agriculture program. West Virginia has remained to use a traditional school calendar with the summer months in recess. Many aspects of the total program suffer and student opportunities are diminished due to being in recess during the most productive months in agriculture. Dennis stated, "Look at all the opportunities we as teachers would have if we were in school those few months. The summer is agriculture's peak season, and it's a shame that we as teachers can't use that to our advantage.” Arthur added,

I think we should go to school year-round. My program, especially horticulture stopped in the summer time and that's when it flourished. My program could have been much more fruitful and the students would have had more opportunities just by being there in the summer. We could run a farmers market, we could have potatoes, tomatoes, great fresh produce. We could work all week, and then go to market, or even have a market at school! Just think about what we could do with landscaping. Could you imagine having a landscape crew with kids with a mower and actually getting paid to do that? We could set up a co-op and farm kids out and they get to set up their own company. And those kids become, after they graduate, business owners. Isn’t that what we want as a state? Don't we need that? It’s a shame because once summer starts, our programs stops. 
When discussing working as teacher in multi-teacher department, it was noted that even though there are great perks to that type of program, it also poses other challenges with respect to collaboration and unity as a whole. Edward noted, "When you work as a single teacher department, you get to be autonomous. When you add another teacher or two to the mix, it becomes a very delicate balancing act.” Barry added, "We were all in some way separate, but overcame that challenge by having a unified vision for the department. That's the only way to survive as a multi-teacher department.” Arthur described the change that occurred over the progression of his career,

When I started, I felt like they were my dear and genuine colleagues. Over time and the change of people, I found that situation had changed and a great divide within the department occurred. A total lack of professionalism, lack of teaching skills and lack of complete vision and unity for the betterment of the students. Dennis added that even though it was challenging to work with other teachers in the program, they maintained civility,

There was one teacher who wasn't as involved with the program. He made himself known and helped out, but he had a lot going on outside of school. We didn’t think much of it at the time, but he just didn't have the time to devote his life to the program as we did. That made it a little more difficult challenging I guess on, our part of it but we got along.

Burnout was noted as a challenge faced by the agriculture teacher throughout the entirety of a career. The concept of burnout was described by Arthur as “A feeling that you've given so much, you don’t want to keep on doing it anymore. The work becomes mundane, and it’s nearly impossible to stay motivated.” Edward added, “There is such a 
thing as burnout in agricultural education because it's not the typical teaching job. It's hard for those outside the profession to understand that. You just have to stay motivated." Barry noted his experience with burnout and its effect on his life as a young teacher, When I started, I didn't realize the challenge of burnout. For me, we were at the school probably four nights a week. It was just kind of one of those things you did and didn't think any different of it. Later on, you look back and realize that you let your family down a little bit, even though they turned out okay. It’s a challenge as a young teacher to take care of the home life. You have to spend some time there, probably do a better job at it than I did.

Combating burnout as an agriculture teacher was noted as a challenge that must be overcome in various stages. Challenges and obstacles presented by burnout can often be remedied by motivation and finding success from within. Barry stated,

It's tough to come up with one thing to combat burnout, but I would have to say motivation would be it. If you don't get stagnant with “this is what I teach ever year, every year, same old stuff” it’s much easier to deal with. I think career and technical education and careers or those fields of work are conducive to that. You have to keep updating. I think you have to change and update based on the needs of your community, or where the skills are needed in trade. Just by doing that, you will keep from getting burned out. For example, if you have a little glitch in your program, change from just stick welding and go into tank welding. Change, I think, will keep you motivated, although change for the sake of just change is not good either. Little perks like that will help you stay in the career and be happy doing so. 
Edward added,

I was motivated to build a program that I was proud of, and thankfully that made me fortunate to never feel burned out. I think you also prevent that feeling by developing memories and living with them. Develop great memories, that's what keeps us going. That's what keeps me going as a retired person. Over my career, I’ve been blessed with many great memories of my students, and I can gladly say that it was all worth it. But we must understand that burnout is something that you have to be very cautious with. I've been fortunate to have cooperation from my wife and family, as well as support from the community and that has helped prevent it. If burnout happens, and you can’t control it, you need to do something else. In that case, you aren’t leaving the profession because you don't believe in it, you're leaving because your health, both mentally and physically may be in danger and life is too precious to risk those things.

Theme 5c: Balancing life. When reflecting back into their careers, the teachers were adamant about how important time and balancing professional and personal obligations had an effect on their careers. Directing a total agricultural education program requires an immense amount of time both in and outside the classroom. Arthur stated, “Well, it's not an 8-4 job. It's whatever it takes. Some days are longer than others, but it just comes with the territory.” Charlie added,

It's definitely a full-time job. The bell rang at 3:15 and by 3:20 the other teachers have already left and you never saw them again till the next morning. And they have their fishing boats on the weekend. You sat back and saw that and asked yourself, "I wonder what that life is like?" 
Even without any planned events or competitions, agricultural education programs often require attention after hours and on weekends. Arthur stated,

Outside of teaching and directing the FFA, the greenhouse ate up most of my time. People didn’t realize that I was there babysitting it on Saturday and Sundays. I went every day, every day to school to check on it even on Christmas. I was there checking on it before most people were out of bed and that was on the weekdays too. I never really noticed how much time I actually spent running to the greenhouse until I retired. My wife felt the impact before I did and enjoyed the extra free time. She pointed out every time we had to go anywhere; we always had to go to the greenhouse first. I guess you just lose track of that time over the years.

Edward noted that if it weren't for all the time and extra hours that ag teachers put in, the programs wouldn't be half of what they are. He stated, The biggest challenge is I think, is how you deal with all the time that you have to put in to your program to make it successful. We have an opportunity to change the lives of kids. We as ag teachers must understand that the job is very demanding and greatly involved. Being in the profession means a restraint upon your time. That's how the program is made. Pardon me, that's just how it's made. You cannot change the fact that there is 24 hours in a day. You can't change the fact that you probably should eat breakfast, lunch and an evening meal somewhere around 5:00 or 6:00. And so, if it happens at 8:00 at night, consistent at night, you have a restraint upon your time. 
When discussing the importance and need for balance professionally and personally, it was noted by the teachers that establishing and maintaining that balance is key and vital to longevity in the profession. Barry stated, “You're not going to be an Ag teacher for 30 years if you don’t have balance. You must take care of that or you will be driven from teaching Ag.” Arthur added, “Personal life was tough with two little kids at home. It’s different now, but they would be crying as you left for convention. I didn’t want to go, but had to. It was really tough.” Dennis added,

Well, it's tough. You have to find balance, to say how you find it, I don't know for sure. But, you try to incorporate things to make that balance. Like, when I would make supervisory visits, I would take my own children with me. My students also knew that on Sunday morning, I went to church and they respected that and understood that I had obligations. I'd probably get fired today for doing this, but sometime in March, we encouraged everyone in the FFA chapter to go to church together on a chosen Sunday. It wasn't required, but we encouraged it and it was an activity. So, I got to compromise a little bit on that side of balancing my life [sic].

Balancing both professional and personal life obligations was noted by the teachers as a struggle during the beginning of their careers. As time progresses within the career, time management and balance becomes less of a struggle and more of a basic, daily routine. Barry noted,

As a new teacher, I struggled with balancing my time and probably should have done a better job at it. You had to be careful and not forget about your family, which we had a tendency to do back then. We had had the tendency to forget 
home, family, because you were so involved in kids. We generally spent at least four nights a week at school working on activities with the kids. Although it took away from family time, it was definitely rewarding. They became my second family.

Overall success in balancing time of the professional agriculture teacher was greatly attributed to a strong spousal and family unit. Arthur stated, "The only way that I was able to make it in the life of Ag teacher was because I had a good wife. I mean she's it, I’m serious!” Edward added,

I was able to make it as a teacher for decades because I was fortunate to have a loving, caring wife and an understanding family. It was easy when I was single, but things drastically change when you say, "I do.” The prosperous balancing act started with my wife, and we worked together at it. We sat down, talked about what all was involved and had that conversation early. You have to ask yourself, is it worth it? And if she disagrees, I should be very honest; she's calling the cards. But if you work it out as we did, you have no problems. You don’t want any problems or trouble at home. You don't want any trouble there, because it's going to lead into your life at school and then it gets complicated. It worked out for the best, and I find myself very fortunate.

Looking back into their careers, the teachers were adamant that you have to make a conscious effort to make time for yourself and family. If you take time out to enjoy life, the likelihood of burnout decreases and satisfaction with balancing professional and personal obligations becomes heightened. Edward added, 
I think you need to take time off for a vacation and get away from it all. It's important that you have a chance in the summertime to take a vacation, get away from it, and leave the stress behind. You may go to the mountains to trout fish, or whatever is in your likings. But you I think you need to do that, because it’s like the old commercial slogan "You must put a new tiger in your tank." I fell that it’s very important and helps prevent burnout.

Charlie emulated the idea of keeping time out for your family. He noted, I'm thankful to have a very understanding wife. Otherwise, I'd have been divorced a long time ago. She'd have left me. At first, I did a horrible job of taking care of my obligations at home. I gave everything to the school. In fact, the principal called me in one day and said, "You need to spend more time at home. Trust me. My first wife left me because I lived at the school. I went home one day and she was gone. You spend too much time here.” I thought he was crazy at first, but looking back on in retrospect, he was correct. I was worried that my son wouldn't want to teach because he saw how I put in 18 hours a day consistently. I'm a way better grandpa than I was a dad. I'm there more.

Theme 5d: Continuing education. Every agriculture teacher in the study recognized that continuing education through pursuit of higher degrees was important. The data that were collected through the informal interviews provided evidence that the primary motivation for obtaining a higher degree was financially driven. Although the primary motivation was financial in nature, increased knowledge and experience was noted as a benefit of obtaining a Master’s degree. Edward noted, “Getting the Master’s becomes extremely beneficial to a person, not only financially, but also educationally.” 
University supervisors recommended taking classes and pursing advanced degrees before the teachers graduated from their undergraduate institution. Charlie noted, "The first thing my advisor told me, “Now, you get out and besides everything else you're supposed to do, immediately, you need to start taking classes.” So I tried to build the program and take classes, it was tough.”

Financial value is a key motivating factor for pursuing advanced degrees. Arthur stated, "Money definitely motivates a teacher." Charlie added, "I looked at the pay scale and saw what just having a masters would do to my salary. Didn’t take me long to make that decision.” Dennis emulated the reason for advancing his education by noting, "The bottom line was that I made more money. That's what kept me in teaching. I encourage all new teachers to do it as sooner rather than later.” In addition to financial motivation, the teachers recognized that obtaining their master's degrees helped them tremendously as a teacher. Dennis stated, "It helped me better prepare for what I needed from a production standpoint, plus some advanced classes on educational philosophy.” Charlie added,

Even though I didn’t do the traditional Master's related to agriculture, I took a lot from it. Through many communication classes, I picked up on a lot of little things in the classroom and laboratory. I think it made me more observant as a teacher and the ability to interact with some of the students that I hadn't been able to get before. I think it was very positive. 
Theme 5e: Career highlights. During the formal interview process, the teachers shared many experiences and stories about the highlights of their careers. These highlights were noted as a key factor in their overall satisfaction and enjoyment directing a total agriculture program. When asked about the memorable experiences that highlighted their careers, the teachers expressed that many of those experiences evolved around the FFA. Edward stated,

I'm very elated about all the success I had with FFA. I feel good about all of the state FFA degree recipients. If you were to go back to my old classroom, you will see their names, hanging on the wall in beautiful order. To me, that is a motivation to those young students coming in today.

When discussing highlights through student achievement, the teachers were adamant that some of the highpoints in their careers was being able to see students be competitive and succeed on a large scale. Dennis stated, “Whenever you're standing on stage at a proficiency award, and you're one of the top four in the nation, out of 450,000, the rest of your life you can crow about that. One of the highlights of my career.” Charlie noted that highlights were persistent throughout his career. He shared his crowning experiences with award winners,

I am most proud of my first proficiency award winner because I didn’t think that was ever going to happen. Those kids excelled in their agriculture program and did a good job with record keeping and were rewarded for their effort. That meant a lot to me because it involved what they had done in their SAE, what they'd done in their record keeping, all their different activities. That was probably the most fulfilling because it was kind of the reason for the agriculture program. 
Competing in contests at both the state and national level was noted to be a great highlight of many of the careers. Charlie stated, "When the kids begin to see success, then they began to expect success. And as long as they're willing to expect it and work for it, I can’t ask for more as a teacher and a proud advisor. Edward noted, I never will forget standing in Kansas City, and that's where it all happened. We found ourselves standing on the stage as the top four parliamentary procedure team in the entire nation. There's nothing like it as far as I'm concerned. It did a lot for those kids, but it did a lot for me as their coach. Many of the teachers highlighted their experiences of not actually competing, but the travel associated with going to competitions and activities. Arthur noted, "When we traveled, we became a family. We got to see each other every day. I miss those many quiet times in the van even though I never thought that I would.” It was noted that for many of the students, traveling with their agriculture teachers was the first time that they had been outside of their communities. Exposure of the outside world had a positive impact on the students. Dennis stated, "One student had never stayed at a hotel before. He wanted to sleep on the floor because he had never felt carpet before. We as teachers don't think about that. It changed how we both looked at life. Barry noted,

One of the greatest highlights of my career was the competitions and traveling. Getting the students out of the community, out of their close knit community and taking them to Kansas City or Louisville. I loved seeing them do well and come back with an attitude of "Hey, I can really do something with my life" and they do. They go out and get good jobs, and most of the times make more than you, but 
they appreciated that experience and how it changed them and come back and let you know that they appreciate you and what you did for them.

After many years of teaching high school agriculture, the teachers expressed that one of the highlights of their careers was the ability to teach multiple generations. Arthur stated, "For me was teaching the offspring of former students. You start having kids of the kids, and their kids and it's so neat. Sometimes, you have students who end up being your administrator. Talk about the circle of life.” Charlie added, "It’s highly gratifying having the children of former students in class. Well, most of the time, the second one is better than the first one. I told them, "Y'all are a lot better than your parents were. How neat!” Edward shared how travel impacted many lives including his own, I remember years ago taking a group of kids to Kansas City, back in the day when you drove everywhere. I will never forget, we were travelling, we got out into that flat country, and he told me one morning, "You know, it just looks like the sun came up out of the ground.” I thought, “He’s never seen this. This is his first time to see this beautiful flat land.” That experience was very important because it changed how I looked at a lot of things in agriculture education. We must give students this opportunity to go beyond their little world, or beyond my little world, and I tried to do that.

Reflection back into the career after retirement elicited many highlights that were noted as fulfilling and satisfying. The teachers were adamant that many of their favorite and most memorable highlights have come to fruition after retirement. Arthur stated, "I love seeing former students and them telling me, "I understand what you were doing, and that had a huge impact on my life.” Barry noted, 
For me, the best highlight for me was the kids just coming back to see me, appreciating what I did for them, and most of the time apologizing for not working harder. I also enjoy seeing students grow and hearing tell students tell their spouses, "See that guy over there in the red coat? He's the reason I've got every job that I have.” What an amazing feeling to have been considered an important part of a child's life. That's what it's all about.

Charlie added,

I had a student who came from a bad foster family situation. He won a proficiency his senior year, and after that he moved on, hadn't heard from him in 20 years. Just recently, he called me up, told me that he had had moved out of state, got married and had a few kids. He told me that his daughter was the president of her local FFA chapter. She had been preparing for a parliamentary procedure contest and needed some help, so he looked me up so that she could ask me questions. So, that means a lot. Just that he would think that, "Well, here’s an individual who helped me, maybe he can help you.” That makes my whole career worthwhile.

Theme 5f: Satisfaction of career. The agriculture teachers agreed that one of the major highlights of their lives was being satisfied with their careers. Each of the teachers noted that after they retired, they felt satisfied with their life accomplishment within the profession. Dennis stated, “I’m super satisfied. I’m glad I become an Ag teacher and wouldn’t change anything about it. To me, it wasn’t a job; I had fun every day and still enjoy it. To this day, I still appreciate my students.” Arthur noted that he was satisfied with his career because, "Each year something was different because of all new kids. Same game, just different players each year." Barry commented, "Being able to provide 
quality instruction so that they can go out and get a job and to raise their family on. I think that's probably the most satisfying thing any teacher could want, success.” When discussing the timeliness of career satisfaction, it was noted that satisfaction was ongoing throughout the career, but was more pronounced after retirement. After retirement, teachers have an opportunity to look back and fully appreciate the magnitude that they had on their program and the profession as a whole. Charlie noted, "I guess satisfaction is most pronounced now, because after you retire, all you have to do is look back and enjoy.” Dennis stated, It's gotten way better since I've retired. Not always, but in a lot of cases, a handshake isn’t good enough, it’s a hug, and that means something. Satisfaction was while I was teaching and then also, I'll say the satisfaction has increased since I retired. Before, it was the satisfaction in knowing that they had been successful students. Now it's satisfaction of knowing that they are successful in life and, in many cases, community leaders. If I go to the fair meeting, just about everybody in there is a former FFA member and student. You can't beat that. Charlie added, Well, I think it was there when it occurred, but in the spur of the moment, and the way everything was going, I don’t think I took the time, I don’t know if it registered or not. Now that I've had time to think about my entire career, and add up all the students, awards, officers, and contests, it seems a lot bigger now. Student success was noted as a prime motivation for having career satisfaction. Dennis added, "It's a great feeling knowing that you changed their life. Shoot for the moon, and if you fall short, you're a shining star.” Agriculture teachers often enjoy getting to see 
their students grow and mature after they have left high school. Charlie noted, "I’ve had many successful students. Some went into business, many went into agriculture. To me, that's neat. I think, at least they saw that there was something there that maybe helped guide them or directed them a little bit.” Edward added, It had to be the success that I have seen students accomplish. It has to be that. That overcomes any failures we had, just the opportunities that I had to put kids into a performance situation where they actually rose to the top. There's nothing greater to me that keeps me going than that. You find satisfaction when it's your desire to like kids and move them up the ladder of success and when you see that happen, to me there's nothing greater. When I see a student out in public, or hear about them being really successful, I think to myself, "I believe a little part of him is a little part of me. I see a little part of me in them.” It's also found when adults realize that the success you gave them helped them in life. When they come back and tell you this, I think that's proof. I just can’t feel that they regret what they've done. That's very satisfying.

The teachers felt that even though many factors played into the overall satisfaction of their career, understanding that teaching agriculture was a true calling was the most satisfying. Barry noted, “Agriculture gave me a good job. It was a good, very rewarding career. In essence, it was a calling.” Charlie stated, I have always thought that the true reason for going into the profession was because they're many great agriculture teachers when I was in high school. But I found that teaching agriculture was a calling. If you were just looking for a job with the same degree, you could get a job that probably is going to pay you a lot 
more somewhere else. But to be able to work with students and see what all they go through, that made it all worthwhile.

It was noted that even though teaching agriculture is a calling, agricultural education is more than just being a teacher. It is about being a mentor and individual who changes the lives of children forever. Edward noted,

This profession was more than a contest; it was more than just winning an award. It taught them that they have another dimension in their brain that they could use and go out and work hard. And if you work hard, you can be extremely successful. I sort of used to make the comment, "We're going over the hill. We need to go over the hill, see what's on the other side.” And they would probably tell you that today, “Thanks for opening up a new world for me.” We can sort of live in our own little world and think we're so very important and that we've got the world by the tail. Until we see what's out there, I think we as FFA advisors, agriculture teachers have the opportunity to expose students to the real world more than anyone in the world.

Theme 5g: Retirement. When discussing retirement from the agricultural education profession, it was noted by the teachers that there were multiple factors that led them to retire. Furthermore, the teachers shared their perceptions of retirement, transitioning out of a career and life after leaving the profession. Retirement is a goal that agriculture teachers have from the first day they enter the profession. Charlie stated, "From day one, I knew I was going to retire, eventually. For me, it was good thing. It was just time.” The length of one's career and decision to retire is based on multiple factors such as experience, attitude, and financial feasibility. Dennis stated, "I knew that I was 
going, or reasonably certain, the first day I could retire. And so when that magical day came, the day after I turned 55, I retired. I also had to consider the financial aspect.” Arthur added, "I never wished my life away. I was ready to retire, because I wanted to focus on my own agricultural enterprise, and I was ok with that.” Edward added, I looked forward to retirement. Not that I was getting worn out. Not that I was burned out, but it comes a time in your life when you say, I'm fortunate to have all so many years [sic], still have good health, and so, I need to turn it over to someone else.

Teachers in the study perceived their retirement from the profession as positive, fulfilling and timely. Edward noted, "My perception of retirement was, I don’t want to quit, and I'm still physically involved with agriculture. My wife, family and I get to do the things we want to do, so we're happy. It was a positive move.” Barry added, I was happy with myself, what I gave to the program, and was at peace with my decision to retire. I had to tell myself, "I gave it 110\%." And if that waivers a little bit, you have to let that go. Once you make that decision to retire, you can’t say, "Boy I wish I had stayed,” or "If I had stayed, this would’ve happened.” You can't predict that. The timing was right, and the move was very positive. When discussing the decision on the timing of retirement from an agricultural education career and the motivation to do so, it was noted by the teachers that each case, each person is different. Arthur noted, "The change in the retirement system motivated a lot us. It became more cost effective to retire than to actually work.” Dennis stated, Teaching agriculture is a young man's game and I didn’t. I figured that the last 10 years of my career wouldn't be as enjoyable because of my age and motivation. I 
made a decision that I wanted to go out on top, and felt that I did. I was confident that I left the program in great shape, ready for the next teacher to take over. My last ten years were more enjoyable than I thought. We set the record for the lowest score on the sweepstakes. Records were meant to be broken, and we had just about every record there was to be had, and it was time to retire because I was on top.

The teachers described a culture for involvement with agricultural education that had been developed after they retired from the profession. They noted that it was important to continue to stay involved within the profession. Edward noted, "I do think it's important, that we as retirees continue to serve the profession. We have invested so much, and it's important to help the next generation.” When discussing their involvement, some noted that they enjoyed remaining in close contact with teaching and FFA whereas others noted that their involvement had waned. Arthur noted, "I enjoyed my time, and just enjoy seeing my former students and their successes.” Barry added, “I’m still fairly involved. I attend board meetings and serve on the LSIC.” After retirement, agriculture teachers enjoy participating in activities such as training teams, judging contests and assisting with livestock shows and alumni organizations. Charlie stated, "I still enjoy getting to help train teams. Even if I have other things going on, I am fairly easily convinced to help out. I guess I kind of miss it, some days.” Dennis noted,

I get out and help with judging hams and bacons and other contests. It feels good to be there to watch the future of agricultural education but still know that you've got it. It's nice to be called upon for wisdom and guidance in those situations. I 
guess it's really hard to fully detach yourself from it. It will always be a part of my life. I'm a lifer for sure.

It was noted that the desire to remain active and involved within the profession is most certainly a very personal decision. Edward stated, I think it's important. It's a very personal choice, but my choice is that I want to stay involved and support the kids as well as still be involved in agriculture. I'm proud to remain active in agriculture and FFA. I spent so many years of my life promoting it. I like to sell produce in other areas, and I'm elated to have that opportunity. I've been beyond blessed to be asked to come back and do some judging in FFA and I'm glad to do it. I still remain active in livestock and enjoy judging fairs in the summertime and I love it. It's nice to get out and even travel to other states to judge and see the agriculture industry and profession thriving. I like that.

Dennis added,

Even though I still am active, I think it’s important for a retired agriculture teacher not to interfere too much. At first, I never darkened the door and never went back. I went to a couple of banquets after I retired, and asked me to come back to help after a few years had passed. I think it was it is important to let the new blood run the show and not dictate what they should do. I felt that I shouldn't go back until all my kids were gone and did just that.

After retirement, some teachers remain active within the profession by returning to the school system as a substitute teacher. By working as a substitute teacher, retired teachers remain active within the teaching profession and can earn additional income to 
supplement retirement. It was noted that substitute teaching allows Charlie stated, 'I’m back as a long term substitute, I hadn’t planned on it, but given the circumstances, I needed to go back and help out. It's nice to get out and about.” Dennis added, “Even years after I retired, the superintendent is begging me to come back and sub. I had everything ready to do it at one time, and decided against it.” Edward stated,

As a teacher and individual in the profession, it's extremely important to go back and sub. If you're getting out of teaching and you're so glad to be out of it, then stay away from subbing. To me, it’s a personal choice; I wanted to support the kids and the community. I think it's very valuable because it keeps you mentally and physically alert.

The agriculture teachers expressed many feelings and emotions about the impact of retirement on their lives. Even though they agreed that they were satisfied by their decision to retire, it was noted that the change was arduous and adjustment into retirement presented multiple challenges. Arthur noted, “I don’t think I realized how much time that I would have. That took a while to get used to. It's hard to leave something you've done so long. But I'm happy.” Charlie stated, Retirement for me was a good thing. And still, don’t miss paper work, don’t miss lesson plans, none of that. It used to be in the fall, but now when June rolls around, I hear of all the teams training to go to the state contest and it brings back some strong emotions. I think to myself, “Oh, if I had a group, I could be training this team, or that team and be successful.” I think about that or think about working on degree or proficiency applications, and all the sudden it takes fun out of it real quick. 
Dennis explained the feeling of walking away from a prosperous career and life that was connected to agricultural education for decades,

Well, the feeling that I had was I'd left it at the top, or near the top, and whoever took over would have to advance it to a higher degree, which would be good. The other thing that I missed a little bit was the contact, the daily contact. The ritual, at 7:30 every day, I was at school, you miss that ritual. But after a while, you work yourself out of that. Unfortunately, I get further removed from the program by retirement and that is hard to deal with sometimes. The most important thing to me now that I've retired are all the former students. They want to shake your hand and talk to you. They still come up to me in public and talk, and share memories about the past and how they are doing in life, that's what makes it for me. It's such a great feeling that you've made an impact on them and they remember you for it.

The teachers shared that there was a degree of difficulty and adjustment that they experienced after retirement. Dennis noted,

The hardest part was the first summer when students called me and asked me advice about different things. I'd give my advice over the phone, but I wouldn't go visit them. I felt that if I did that, I'd be crossing the line with the teachers that were still there.

Edward stated,

The hardest part for me was that once I retired, I had no possession. I mean, possession of the program. When you walk away from it, it was scary, very difficult for me. I still like it, but any accomplishment is not part of me anymore. 
That still scares me a bit. I walk down the street, or I walk into a group of people, and I don't feel important anymore. I'm not trying to be self-centered, but when you have success in a program, and in your profession, you have success, and you're still actively working. You walk in with a group of people, and deep down you say to yourself, "You know, I’m still important, and people still recognize me for that.” When you retire, that disappears. How do you live with that? You live with the memories of your past performances. That's the only thing that bothers me. You don't have any possession of a profession that you used to be such an integral part of.

Theme 5h: Future teachers. As the agriculture teachers shared their experiences of directing total programs, they were adamant that their experiences could help young and seasoned teachers currently in the profession. They shared that the best way to help the next generation of professionals is by looking to the past for guidance. It was noted that one of the most important aspects of being an agriculture teacher is becoming dedicated and entrusted to the local community.

Agriculture teachers, as well as extension agents are often portrayed as leaders within a community. Gaining rapport and trust with the local community is vital to the overall success of being an agriculture educator. Edward stated, "We are most definitely leaders within the community. You have to show that you are of them. If they can relate to you, and see that you are entrenched within the community, you will be successful.” Arthur added,

When I first started teaching, they wanted me to use the shotgun approach and teach a little bit of everything. That was time consuming and get you get so 
consumed at school, that you lose the community aspect of your job. It is vital to gain notoriety in the community very early on in order to pave the way for your success. I became my own person and made a name for myself in the community. One of the best ways to do that is to get involved with a civic organization like the Lions Club. When people see you out in the community, they feel like you are one of them and that impact is more than anyone can imagine. If you work for the community, they will work for you. Once I bought into them, they bought into me.

Barry noted his experience of working with extension agent to help gain an identity within the community,

One of the major components of the county was the fair. You worked very closely with the county extension agent. That pulls all your whole agriculture community together. I wouldn't say that the agriculture community expected you to be there, but in essence, you were. You were expected to be there because that was a major component of your students. You also used working with the extension agent as a tool for recruitment. Their kids eventually became your kids, and due to the overlap with the programs, we shared the kids together, which made for a great relationship.

The teachers agreed that in order to be successful, an agriculture teacher must be and remain committed to the profession. Arthur stated, "Directing an agriculture program is work. You're going to be noticed, whether you do something, or don't do something. You have to know that and be willing to commit yourself for the long haul.” Barry added, "If you're committed, you can make it your program. As long as you're there, it’s yours. 
The connection with the kids and the parents and all those types of things make it that way.”

It was noted that obtaining and putting important skills in agriculture to good, practical use strengthened commitment to the profession. Dennis stated,

If there was anybody that every crowed this, it was me. When I graduated from college and entered into teaching, I felt that I wasn’t prepared. But that wasn’t true. I had the skills, but I hadn’t put them to use yet. You've got the skills, but unless you relate them to the real world, and show a practical application to your students, you don't show commitment to agriculture and they see that. If you don’t use your skills for the betterment of yourself and your students, they won't amount to a hill of beans. You have to know what you've got, so you know where you're going.

The teachers recognized that keeping open communication was an important in order to be a successful agriculture teacher. Charlie noted, “It's important for the community and your administration to know what you're doing. If they see success, they will continue to support success.” Barry stated,

If you're going to survive as an agriculture teacher, you must establish good communication. My best advice for new and seasoned teachers is to get on a first name basis with your administrators, get that communication I guess I would say. Communication between your boss, your administrators, board members and central office staff. Don’t forget about your janitor and secretary. They can be some of the most important people to you because they get stuff done. 
Barry added that open communication with the community and employers was crucial for SAE success, "You have to keep an open dialogue with employers, and they are your lifeline. Sometimes you don’t have students who fit their mold or what they need, and you have to be upfront and honest with them.” Arthur expressed that communication within the community also added support with regards to the advisory committee, "Let them become involved and engaged. Communicate and direct, don't abuse them. They have to feel involved and needed, but if you start telling people what to do, they'll run from you.”

Support from within the agricultural education community was noted as a vital part of surviving and being successful in directing the total program. Agriculture teachers have a distinguished network of colleagues and professionals for whom they rely on for guidance, support and direction. Edward noted, "Even though I had a great background, there were a lot of things that I needed to know still. I wasn't afraid to ask people for help. Dennis stated,

It's a lonely world out there sometimes. In this day in society, you need somebody to talk and lunch with, someone to share your experience with. There is a good chance, they've experienced it and can help you. I understood later that it was important, but I probably wouldn’t have thought it was important unless I had talked to them.

Barry added that networking with other agriculture teachers was one of the highlights of this career,

Our network as agriculture teachers was tremendous and it's unique the profession of teaching. Other teachers wish they had this strong camaraderie. We 
were a real close-knit bunch of teachers. We did things, we got together for picnics and outings where we could share work and family experiences and the wives would share theirs with each other. You could call any Ag teacher up if you needed something and say, “Hey, I'm in, this is the situation I'm in, what did you do? It's much better to seek out advice from you colleagues than to go the road alone. They've already traveled it.

Even after retirement, the agriculture teachers expressed that not only current teachers, but also administrators often seek them out for advice and guidance as well. They noted that the continuance of support was important for helping those still left in the profession. Edward stated,

I think it's extremely beneficial to be called upon for guidance and wisdom after retirement. We still, on most days, have a good mind, don’t put us out to pasture. But we have to understand that we are old in the profession, we have to understand that we were there also at one time. And, that we did survive because we did seek out help when we needed it. Don't let it drive you out of the profession, then it becomes your fault that you didn't reach out for help. 


\section{CHAPTER V}

\section{Conclusions}

\section{Purpose of Study}

The purpose of this study was to determine retired agriculture educator's perceptions on the various challenges, barriers, as well as successes and satisfaction of directing the secondary school based agricultural education program in West Virginia

\section{Objective of Study}

The objectives of the study are reflected in the following research questions which were used to guide the study.

1. What memorable experiences were present in directing a total agricultural education program?

2. What career highlights were present in directing the total agricultural education program?

3. What challenges and/or barriers were present while directing the total agricultural education program?

4. What was the career satisfaction after retiring from directing the total agricultural education program?

\section{Summary of Themes}

The following themes emerged from the data during the data analysis process: instruction, support, directing FFA, supervising student teachers and perceptions of directing the Total Program. The participants in this study emphasized each of these 
themes in their responses during the formal interviews. Conclusions from these themes are organized as a general conclusion, with recommendations for practitioners and teacher education.

\section{Conclusions from Themes}

Theme 1: Instruction. Instruction is the core standard which provides the foundation for the total agricultural education program. The agriculture teachers in this study believed over the duration of their careers, curriculum had evolved into a more skills-based need for instruction. It was noted that adapting curriculum standards to fit the needs of the students and the community was a challenge but strengthened their overall program. Furthermore, they believed discipline and student evaluation were some of the more notable challenges and barriers during both classroom and laboratory instruction. It can be concluded that agriculture curriculum should heavily emphasize skills based instruction.

Laboratory instruction is beneficial to extend and develop concepts learned in the classroom. Student learning is heightened when laboratories are well equipped and employ the most current technology. The agriculture teachers in the study believed laboratories should be utilized to strengthen student learning as well as serve as an outlet for SAE and fundraising opportunities. They also noted laboratories such as greenhouses and animal processing facilities should be operated as a business to provide students with simulated real-world experience.

Adult education is still a highly important aspect of directing a total agricultural education program. Adult learning establishes continuity of education across generations and was noted as an important opportunity for the community. The agriculture teachers 
believed adult education programming affords adult community members the opportunity to gain knowledge in diverse areas of agriculture and overcome deficiencies affecting their agricultural enterprises. They further noted that collaboration with the local extension agent builds effective adult education programs. In addition, they felt that motivation to participate in adult education programs was monetary in nature. It can be concluded that agriculture teachers need to establish and conduct adult education programs throughout the year to help strengthen the overall total program and community.

\section{Recommendations for Practitioners.}

- Agriculture teachers should adapt curriculum to fit the needs of the students and community.

- Evaluation methods should be established that meet the individual capabilities of students.

- Agriculture teachers should continue to implement labs to strengthen learning and retention.

- Production laboratories should be operated as a business to simulate real-world businesses.

- Agriculture teachers should implement the most current technology into laboratories when possible.

- Agriculture teaches should be actively holding adult education programs.

- Agriculture teachers should survey the adult community to determine needs for adult education programs. 
- When operating an adult education program, agriculture teachers should collaborate with the local extension agent.

- Agriculture teachers should continue to actively train on and implement current technology into classroom and laboratory instruction.

\section{Recommendations for Teacher Preparation and Professional Development.}

- Teacher educators should continue to include curriculum development in a teacher preparation program.

- Teacher educators should engage preservice teachers in effective evaluation and classroom management training.

- Teacher educators should train preservice teachers on using laboratories as businesses to engage students in real-world simulation.

- Teacher educators should continue to implement technology training in a teacher preparation program.

- Teacher educators should continue to include adult education instruction in a teacher preparation program.

Theme 2: Support. The second theme in this study focused on how specific areas of support affect the total agricultural education program. The retired agriculture instructors in this study believed that gaining and maintaining support from all levels of administration, parents, and the community is one of the most important factors of operating a successful agricultural education program. Establishing strong support from all administrative levels such as school, county and state has a direct effect on programs such as funding for programs, facility upgrades, travel, and teacher contracts. The findings indicated that the agriculture teacher should recognize the proper channels of communications within administration and keep communication open at all times in order for transparency between the teacher and the administrators. It was also concluded that 
support from administration is easily attained and sustained by making the students and their success visible to administration at all times such as board meetings and other school functions.

In addition, this study found parental and community support is a driving force of operating a successful and viable agricultural education program. The findings hold that parents have multiple effects on student and program success. The agriculture teachers believed that a strong program base starts with a strong foundational support system at home, which transfers over in the students to the overall program. It was concluded that strong parental support of the student and program influenced positive behavior, which lessened or even eliminated discipline problems in the classroom, laboratory, and extracurricular settings. Furthermore, positive parental support enhanced the overall program by promoting involvement in program activities, supervised agricultural experiences, adult education programs, and fundraising ventures.

Community support of the total agricultural education program was found to be an integral aspect of program development through collaboration with the county Extension agent, advisory committee and community members who provided outlets and opportunities for student SAEs. The agriculture teachers in this study believed that a strong collaboration with the Extension agent fostered a positive environment for adult education and programs in which the student is involved in both the 4-H and FFA programs. Extension agents and agriculture teachers offer specialized knowledge, which can be shared among the clientele in programming and educational opportunities.

In addition, the findings suggest that the program advisory committee is still an integral part of the total program. The advisory committee and its composition of key 
community leaders allow the overall program to be guided to fulfill the needs and wants of the local agricultural community. Advisory committee members should be prominent individuals within the community who are successful, interested, and have knowledge in the area of agriculture. It was noted that the advisory committee should be maintained and be actively involved in order to be an effective part of the total agriculture program. It can also be concluded that supportive community members provide assistance to the overall program by being active fundraisers and supporters of student SAE opportunities.

\section{Recommendations for Practitioners.}

- Agriculture teachers should keep open lines of communications with all levels of administration.

- Agriculture teachers should annually inform their administrators on their curriculum and program.

- Parents should be kept informed, involved and utilized in all facets of the total program.

- Agriculture teachers should collaborate with the local Extension agent(s) to integrate expertise into educational programs.

- The program advisory committee should remain active, engaged, and meet regularly.

- Agriculture teachers should select advisory committee members who are invested in agriculture but offer diverse backgrounds.

\section{Recommendations for Teacher Preparation and Professional Development.}

- Teacher educators and/or cooperating teachers should prepare preservice teachers to effectively communicate with administrators on the school, local, and state levels as well as parents and community members.

- Teacher educators should engage preservice teachers in an advisory committee meeting to ensure that all agriculture teachers have personal experience with advisory committees. 
- Teacher educators should continue to include extension programming in a teacher preparation program.

Theme 3: Directing FFA. Although the FFA is only a small component of the total program, all of the retired agriculture teachers in this study believed directing the FFA within the total program was a major duty within their careers. The findings indicated agriculture teachers are responsible for the administration of the organization, yet all indicated the student members were solely responsible for the overall work and direction of the organization. The agriculture teachers believed that the role of the advisor should solely be to advise the members and students should be allowed to have control of their organization including the election of officers and transaction of business.

All of the agriculture teachers held that SAE programs are vital for student success and program strength. Supervised agricultural experience programs not only have a profound impact on the students, overall program, but the community as well. Although the student's interests drive SAE development, agriculture teachers are vital to help direct students to the necessary resources to be successful. The teachers believed that SAEs were a driving force of student learning and development. It can be concluded that SAEs are not only a way for the student to earn money, but valuable life experience and selfesteem building as well.

In this study, the participants explained the importance of training successful Career Development Events teams and their role in overall program success and job satisfaction. The teachers believed that CDE team selection should be holistic and incorporate mixed methods to procure a strong and diverse team composition. In addition, it can be concluded that CDE team training should not take place during the 
school day but rather after school. Furthermore, agriculture teachers should let the CDE training be an extension of the classroom learning and not include it as part of the curriculum.

Successful CDE teams and involvement in the FFA provide students with opportunities to excel in diverse areas of agriculture while developing new relationships and leadership qualities. It was noted that confidence and critical thinking skills were key products that members develop through participation in the FFA and CDEs. It can be concluded that involvement the FFA is an important factor of overall student success and life development.

\section{Recommendations for Practitioners.}

- Agriculture teachers should continue to promote leadership development through the FFA portion of the total program.

- Agriculture teachers should only advise the FFA chapter and let the student membership guide the direction of the organization.

- When selecting officers for the FFA chapter, advisors should establish a nomination committee and allow the electorate to determine leadership of the chapter.

- Agriculture teachers should implement an initial officer's retreat with newly elected leadership to build and foster leadership development as well as plan for the service year.

- Agriculture teachers should ensure that all students have an approved and active SAE.

- When supervising SAEs, the agriculture teacher should make a formal or informal visit to each student at least twice throughout the SAE year.

- Agriculture teachers should train CDE teams outside of classroom instruction time. 
- Student success within the FFA and CDEs should be showcased at the conclusion of the school year in the form of a banquet or awards ceremony to promote and recognize student success.

\section{Recommendations for Teacher Preparation and Professional Development.}

- Teacher educators should continue to include FFA and SAE instruction in a teacher preparation program.

- Teacher educators should engage student preservice teachers in SAE supervisory visits to enhance and build experience in supervision.

- Teacher educators should continue to educate preservice teachers on how to train successful CDE teams.

Theme 4: Supervising Student Teachers. The fourth theme in this study focused on the perception of supervising student teachers within the total agricultural education program. The agriculture teachers in this study believed that the 12 twelve week student teaching experience length was appropriate for student teachers to receive a quality experience as well as to determine whether or not they want to further pursue the profession of teaching agriculture. It was noted that during the spring semesters, student teachers receive an abbreviated experience because of the amount of activities and experiences that occur after they leave and the conclusion of the site's semester. It can be concluded that an extension of the student teaching experience to a full semester or modification of the time period would enhance the student teaching experience and offer more opportunities to the student teacher.

Feedback and performance evaluations are a critical aspect of supervising a student teacher in the total agricultural education program. Without feedback and evaluation, student teachers wouldn't have a gauge of their overall performance and 
would struggle in identifying and overcoming obstacles or weaknesses within the student teaching experience. The agriculture teachers believed that feedback and performance evaluations were most valuable during a reflection at the end of the school day. Furthermore, they believed that feedback and evaluation meetings should occur daily. More specifically, the evaluation meetings should be a reflection of both the positive and negatives of the day with the agriculture teacher offering alternatives instead of solutions to handling situations that occurred. Therefore, it can be concluded that daily feedback and performance evaluations are crucial to student teacher success, growth, and development.

\section{Recommendations for Practitioners.}

- Agriculture teachers should actively participate in hosting student teachers to offer a variety of experiences for preservice teachers.

- Agriculture teachers who supervise student teachers should allow the student teacher to fully immerse themselves in the total program by turning all teaching and leadership duties over to them.

- Agriculture teachers should involve student teachers in planning, development, and decision-making during the student teaching experience.

- Agriculture teachers should not intervene during instruction unless liability is compromised.

- Agriculture teachers should conduct daily feedback and performance evaluations with the student teacher at the conclusion of the school day.

- During daily feedback and performance evaluations, agriculture teachers should offer alternatives instead of solutions to issues faced by the student teacher. 


\section{Recommendations for Teacher Preparation and Professional Development.}

- Teacher educators should lengthen or modify the student teaching experience to allow for a more enhanced experience.

- Teacher educators should engage preservice teachers in teaching evaluation techniques to ensure that all agriculture teachers have personal experience with evaluating others.

- Teacher educators should prepare preservice teachers on the amount of time and extra involvement that operating a total agriculture program entails to ensure transparency of the professional and co-curricular demands of the job.

Theme 5: Perceptions of Directing the Total Program. The final theme in this study focused on the many contributing factors of directing the total agriculture program. This factors include, background knowledge, challenges and barriers, balancing life, continuing education, career highlights, career satisfaction, and retirement. The agriculture teachers believed that background greatly influences the decision to teach agriculture. Being reared on an agricultural enterprise or involvement in high school agriculture was noted as motivating factors to enter the agricultural education profession. It can be concluded that background knowledge and experience is a significant motivator in making career decisions within the teaching profession.

In the total agricultural education program, agriculture teachers face multiple challenges and barriers that have profound impacts on their overall job and satisfaction. The agriculture teachers believed that many of the challenges and barriers existed from the start to middle of their careers and progressively waned. Challenges and barriers included burnout, limited resources, demand to teach high student volumes, school 
calendar, and working in a multiple-teacher department. The teachers noted that they were never formally trained in how to overcome these challenges and barriers during their preservice teacher training and professional development workshops. Therefore, it can be concluded that preservice and in-service teachers need specific training to help combat and overcome the noted issues that arise during their careers.

Learning to balance time both professionally and personally is a challenge that agriculture teachers face. Agriculture teachers face greater demands for time and involvement than other teaching disciplines. Throughout their careers, the agriculture teachers felt that they struggled to manage both the job and home life and observed negative outcomes of that failure on both areas. The teachers further noted that learning to balance and manage time was the key role to longevity, overall happiness and satisfaction of staying in the agricultural education profession. It can be concluded that agricultural educators need training in time management and balance.

All of the agriculture teachers in this study discussed that continuing education and pursuit of advanced degrees are crucial to development and improvement of overall job satisfaction. It was noted that factors that motivate teachers to pursue advanced degrees include increased financial compensation, and a broader depth of knowledge and experience. It can be concluded that agriculture teachers should continue their education by pursuing advanced degrees, multiple certification areas, and professional development training.

As a whole, the agriculture teachers in this study strongly believed that they were highly satisfied with their careers as agricultural educators. It was noted that career satisfaction was ongoing throughout the career, but became most pronounced after 
retirement. In addition, student success, growth, and development were described as the key motivating factor for being satisfied with the career. Furthermore, the teachers described their careers as a true calling which also greatly impacted their perception of career satisfaction. It was concluded that student success elicits career satisfaction among agricultural educators.

Finally, retirement was described as a positive, fulfilling experience that enhances perception of satisfaction and meaning of one's career in agricultural education. Many factors motivate agriculture teachers to retire including financial stability, health, program success, satisfaction and personal goals and objectives. The agriculture teachers believed that retirement enhanced their lives and allowed them to focus on personal growth, as well as enhanced opportunities to stay involved and give back to the profession in other ways that they weren't able to do before retirement. As a whole, agriculture teachers remain active within agricultural education in a variety of ways. This continued association was noted as an outlet that assisted in the transition into retirement and an opportunity to remain active and supportive to the profession.

\section{Recommendations for Practitioners.}

- Agriculture teachers should ensure balance between professional and personal responsibilities.

- Agriculture teachers should pursue advanced degrees for personal and professional growth.

- After retirement, agriculture teachers should remain active within the profession for professional as well as personal support and development. 
- Agriculture teachers should keep open lines of communication with community members.

- Agriculture teachers should utilize current and retired agriculture teachers to provide mentorship.

\section{Recommendations for Teacher Preparation and Professional Development.}

- Teacher educators should prepare preservice teachers to manage time and provide training for professional and personal life balance.

- Teacher educators should recommend that teachers continue their education and pursue advanced degrees.

- Teacher educators should utilize current and retired agriculture teachers to help train preservice and beginning service teachers through mentorship.

- Teacher educators should develop a statewide mentorship program.

\section{Recommendations for Future Research}

Based upon the findings of this study, the following recommendations for future research have been drawn:

- Further qualitative research should examine the perceptions observed from this study with new agriculture teachers and teachers who have been teaching for 5-10 years to compare results.

- A quantitative examination of current teacher perceptions of the identified factors should be conducted.

- Further examination is warranted that examines the effects of specific factors on job performance and overall satisfaction. 
- Comparison of the identified factors between teachers who taught single and/or multiple teacher departments. 


\section{REFERENCES}

Ary, D., Jacobs, L. C., Sorenson, K. C., \& Walker, D. A. (2014). Introduction to research in education, ( $9^{\text {th }}$ ed.). Belmont, California: Wadsworth.

Bernard, H. R. \& Ebrary, I. (2011). Research methods in anthropology; Qualitative and quantitative approaches ( $5^{\text {th }}$ ed.). Lanham, MD; AltaMira Press.

Boone, H. N., \& Boone, D.A. (2009). An assessment of problems faced by high school agricultural education teachers. Journal of Agricultural Education, 50(1), 21-32. doi: 10.5032/jae.2009.01021

Boone, H. N. (2014). Transitions. WV AG ED News and Views, July-September. Morgantown, WV: WVU Agricultural and Extension Education Department.

Brouwers, A., \& Tomic, W. (2000) A longitudinal study of teacher burnout and perceived self-efficacy in classroom management. Teaching and Teacher Education, 16(2), 239-253. doi: 10.1016/S0742-051X(99)00057-8

Cano, J., \& Miller, G. (1992). A gender analysis of job satisfaction, job satisfier factors, and job dissatisfier factors of agricultural education teachers. Journal of Agricultural Education, 33(3), 40-46. doi: 10.5032/jae.1992.03040

Castillo, J. X., \& Cano, J. (1999). A comparative analysis of Ohio agriculture teachers' level of job satisfaction. Journal of Agricultural Education, 40(4), 67-79. doi: 10.5032/jae.1999.04067

Creswell, J. W. (2013). Qualitative inquiry \& research design: Choosing among five approaches, ( $3^{\text {rd }}$ ed.). Los Angeles: SAGE.

Croom, D. B. (2003). Teacher burnout in agriculture education. Journal of Agricultural Education, 44(2), 1-13. doi: 10.5032/jae.2003.02001

De Lay, A. M., \& Washburn, S. G. (2013). The role of collaboration in secondary agriculture teacher career satisfaction and career retention. Journal of Agricultural Education, 54(4), 104-120. doi: 10.5032/jae.20113.04104

Dewey, J. (1900). The school and society. Chicago: The University of Chicago Press.

Dewey, J. (1916). Democracy and education: An introduction to the philosophy of education. New York: Free Press.

Dooley, K. E. (2007). Viewing agricultural educationresearch through a qualitative lens. Journal of Agricultural Education, 48(4), 32-42. doi: 10.5032/jae.2007.04032

Glaser, B. G. (1965). The constant comparative method of qualitative analysis. Social Problems, 12(4), 436-445.

Glaser, B. G., \& Strauss, A. L. (1967). The discovery of grounded theory: Strategies for qualitative research. Chicago, IL; Aldine Publishing Company. 
Kantrovich, A. J. (2007). A national study of the supply and demand for teachers of agricultural education from 2004-2006. Morehead, KY: American Association for Agricultural Education.

Lincoln, Y .S., \& Guba, E. G. (1985). Naturalistic inquiry. Newbury Park, CA: Sage

Mundt, J. (1991). The induction year- A naturalistic study of beginning secondary teachers of agriculture in Idaho. Journal of Agricultural Education, 32(1), 18-23. doi: 10.5032/jae.01018

Mundt, J. P., \& Connors, J.J. (1999). Problems and challenges associated with the first years of teaching agriculture: A framework for pre-service and in-service education. Journal of Agricultural Education, 40(1), 38-48. doi: 10.5032/jae.1999.01038

Myers, B. E., Dyer, J. E., \& Washburn, S.G. (2005). Problems facing beginning agriculture teachers. Journal of Agricultural Education, 46(3), 47-55. doi: 10.5032/jae.2005.03047

Odell, K. S., Soloninka, J. W., Lawrence, L. D., \& Gartin, S. A. (1992). Life satisfaction of retired West Virginia secondary school agriculture teachers. Journal of Agricultural Education, 33(1), 17-22. doi: 10.5032/jae.1992.01017

Patton, M. Q. (2002). Qualitative research \& evaluation methods ( $3^{\text {rd }}$ ed.). Thousand Oaks, CA: SAGE Publications

Paulsen, T. H., \& Martin, R. A. (2014). Supervision of agricultural educators in secondary schools: What do teachers want from their principals? Journal of Agricultural Education, 55(2), 136-153. doi: 10.5032/jae.2014.02136

Rocca, S. J., \& Washburn, S. G. (2006). Comparison of teacher efficacy among traditionally and alternatively certified agriculture teachers. Journal of Agricultural Education, 47(3), 56-69. doi: 10.5032/jae.2006.03058

Rocca, S. J., \& Washburn, S. G. (2008). Preservice agriculture teacher's perceptions of career barriers and support. Journal of Agricultural Education, 49(2), 28-49. doi: 10.5032/jae.2008.02038

Seidman, I. (2013). Interviewing as qualitative research: A guide for researchers in education and the social sciences. New York: Teachers College Press.

Stephens, C. E. (2001). Report to the Governor on teacher retention and turnover. Standards Commission, State of Georgia, Athens, Georgia. 
APPENDIX A:

Cover Letter 


\section{Dear Retired Agricultural Educator,}

As a retired agricultural educator in West Virginia, you have accumulated a wealth of knowledge through your experiences teaching. During your time in the teaching profession, you may have encountered challenges and successes in education. Knowing and understanding those challenges and successes are vital to help those entering and currently in the profession.

I am Dylan D. Johnson, a graduate student in Agricultural and Extension Education; and under the direction of my advisor, Dr. Stacy A. Gartin, we are conducting this study to determine the challenges, barriers as well as successes of directing the total agricultural education program in West Virginia through the eyes of those who have retired from the profession. The results of this study will be used to prepare a thesis to partially fulfill the requirements for a Master of Science in Agricultural and Extension Education.

We are contacting retired agricultural education teachers who taught in West Virginia for this study. The results will provide insight on the challenges, barriers, and successes of teaching high school agriculture in West Virginia from a unique perspective of the retired professional. The results will also be used to assist pre-service teacher educators, state supervisors of agricultural education and educational leaders determine areas of the profession that need to be addressed to enhance program effectiveness and teacher efficacy.

Participation in this research study is completely voluntary and all information you provide will be held as confidential as possible. The personal interview should only take a few hours of your time and your participation is crucial to the success of the study. Your personal responses will be reported in a summary format and will not be identifiable.

The Institutional Review Board (IRB) at West Virginia University has approved this research study. If you have any questions or concerns about your participation in this study, you may contact me at djohns40@mix.wvu.edu or 304-293-5488.

Because this is a personal interview based study, I will be contacting you before January 15, 2016 to set up a meeting time at your convenience in which we can complete the interview. Thank you in advance for your assistance with this research effort. We sincerely appreciate your participation.

Sincerely,

Dylan D. Johnson

Masters Student

Education
Stacy A. Gartin, Ph.D.

Professor

Agricultural and Extension 
APPENDIX B:

Interview Guide 


\title{
INTERVIEWER GUIDE
}

\author{
Directing the Total Program of Agricultural Education
}

As Perceived by Retired Secondary Agriculture Instructors

In West Virginia

Interviewer reads: Hello and welcome to our session today. Thank you for taking the time to join our discussion about teacher perceptions of directing a total agriculture program in West Virginia. My name is Dylan Johnson, and I am a graduate student at West Virginia University studying agricultural and extension education.

Before we begin, let me share some things that will make our discussion easier. There are no right or wrong answers. Please feel free to share your point of view. Please speak up and clearly. I am audio recording the session because we don't want to miss any of your comments. The tape will not be heard by anybody other than myself and a third-party transcriptionist. Once the tapes have been transcribed, the audio recordings will be destroyed. We will be on a first-name basis, and in our later reports your name will not be attached to the reported comments. You may be assured of confidentiality.

My role here is to ask questions and listen. I will be asking you around ___ questions. Our session will last about ___ hours. I want to make sure we cover all of the questions. Let's begin.

\section{Directing the Total Program of Agricultural education}

Interviewer reads: One of my research interests are centered on learning from the past to help shape the future of agriculture education. I am very intrigued by the stories and experiences of past educators and with that knowledge and experiences, those involved in teacher education can help properly train the next generation of agriculture educators. Since you have worked and retired from this discipline, I would like to ask you a few questions about your experiences directing agricultural education programs.

1. Describe your experience directing a total agricultural education program?

- Probe: How many years did you teach agriculture education?

- Probe: What did your total agriculture program encompass?

2. What were the highlights of your career in directing a total agricultural education program?

- Probe: What made those highlights so memorable or significant to you?

- Probe: How did outside factors affect the success of your program?

3. Please share with me the challenges and/or barriers that you experienced while directing a total agricultural education program?

- Probe: What effect did local and state administration have on your program?

- Probe: How did changes in technology affect your experience? 
- Probe: What challenges did you face in the first 5 years opposed to the last 5 ?

4. Now that you have retired, and have had an opportunity to look back on your career, how satisfied were you with your career?

- Probe: Was that perception different before you retired?

- Probe: Was that satisfaction present as experiences happened or now after you have left the profession?

- Probe: What contribution to your program instilled the most satisfaction?

\section{Concluding Discussion}

Today we've talked about your experiences directing a total agricultural education program:

- Are there any other experiences that you haven't discussed prior that you would like to share with me?

I am now going to summarize the main points from today's discussion: (Interviewer lists the key messages and broad ideas that developed from the discussion).

- Is this an adequate summary?

Interviewer reads: As I explained in the beginning of the session, the purpose of this research study was to gather valuable information your experiences in directing the total agricultural education program. Your comments today will aid in future teacher education for agriculture educators.

- Have we missed anything or are there any other comments?

Interviewer reads: Thank you for taking time out of your day to share your opinions. Your participation has greatly appreciated and has provided valuable information. 


\section{BIOGRAPHICAL SKETCH}

Dylan D. Johnson was born and raised in Flatwoods, West Virginia where he attended Braxton County High School. During Dylan’s high school career he was an agricultural education student and an active FFA member and officer of the Braxton County FFA Chapter.

Following graduation from Braxton County High School in 2010, Dylan enrolled as an undergraduate student at West Virginia University (WVU). While at WVU, Mr. Johnson was an active member of the Mountaineer Collegiate FFA Chapter and was inducted into the WVU Alpha Tau Alpha honorary fraternity chapter. In 2014, Dylan began his student teaching at the Taylor County Technical Center at Grafton High School in Grafton, West Virginia under the supervision of Mr. Stephen Tennant. In May of 2014, Mr. Johnson graduated with his Bachelor of Science Degree in Agriculture with a major in Agricultural and Extension Education, Magna Cum Laude from West Virginia University. Later, he was awarded a teaching certificate by the West Virginia Department of Education in agricultural education, grades 5 through adult.

Following his graduation from WVU, Mr. Johnson accepted an assistantship with the Davis College of Agriculture, Natural Resources and Design’s School of Design and Community Development at West Virginia University. In 2014, Dylan began his work on a Master of Science degree focused in agricultural education under the tutelage of Dr.

Stacy A. Gartin. During his Master of Science program, Dylan was the lead instructor for AGEE 110: Microcomputer and Other Technology Applications in Agricultural Education. In addition, he served as a graduate teaching assistant for AGEE 421: Agricultural and Natural Resources Communications, AGEE 103: Basics of Ag 
Mechanization and AGEE 101: Global Food and Agricultural Industry for Dr. Harry N.

Boone and Dr. Stacy A. Gartin. In May of 2016, Mr. Johnson graduated with his Master of Science from West Virginia University. 